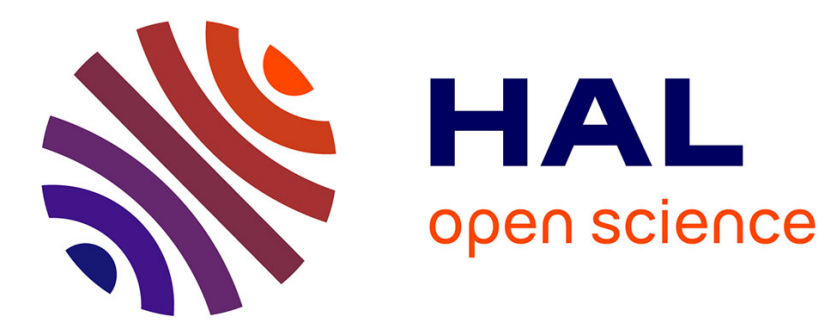

\title{
Photoswitchable phosphines in catalysis
}

Fabrizio Medici, Nawel Goual, Vincent Delattre, Arnaud Voituriez, Angela

Marinetti, Mr V Delattre

\section{To cite this version:}

Fabrizio Medici, Nawel Goual, Vincent Delattre, Arnaud Voituriez, Angela Marinetti, et al.. Photoswitchable phosphines in catalysis. ChemCatChem, 2020. hal-03021745

\section{HAL Id: hal-03021745 \\ https://hal.science/hal-03021745}

Submitted on 24 Nov 2020

HAL is a multi-disciplinary open access archive for the deposit and dissemination of scientific research documents, whether they are published or not. The documents may come from teaching and research institutions in France or abroad, or from public or private research centers.
L'archive ouverte pluridisciplinaire HAL, est destinée au dépôt et à la diffusion de documents scientifiques de niveau recherche, publiés ou non, émanant des établissements d'enseignement et de recherche français ou étrangers, des laboratoires publics ou privés. 


\title{
Photoswitchable phosphines in catalysis
}

\author{
Fabrizio Medici, Nawel Goual, Vincent Delattre, Arnaud Voituriez* and Angela Marinetti*[a]
}

[a] Dr A. Marinetti, Dr A. Voituriez, Mr V. Delattre, Ms N. Goual, Dr. F. Medici

Université Paris-Saclay, CNRS, Institut de Chimie des Substances Naturelles, UPR 2301, 91198, Gif-sur-Yvette, France.

E-mail: angela.marinetti@cnrs.fr; arnaud.voituriez@cnrs.fr

\begin{abstract}
Photoswitchable catalysts based on phosphorus ligands have been overlooked so far, despite the growing current interest for catalysts control through external stimuli. This review surveys the current knowledge in the field, including synthetic approaches to photoswitchable phosphines and their transition metal complexes, and applications in rhodium, palladium, gold, ruthenium and copper catalysis. This survey demonstrates that both regulation of the catalytic activity and tuning of the chemo- and enantioselectivity can be achieved using irradiation as a non-invasive external stimulus. Non-catalytic uses of photoswitchable phosphines in organic synthesis are also mentioned.
\end{abstract}

\section{Introduction}

Molecular photoswitches have received attention as suitable tools for the non-invasive, external control and modulation of biological systems, ${ }^{[1]}$ as well as for the miniaturization of key technologies: nanoscale electronic devices, ${ }^{[2]}$ artificial molecular machines, ${ }^{[3]}$ functional materials ${ }^{[4]}$ and energy storage devices, ${ }^{[5]}$ among others. Moreover, photoswitch phenomena have been considered in the field of homogeneous catalysis, with the aim to mimic the dynamic behaviour of bio-catalysts that regulate their catalytic activity via subtle conformational changes. ${ }^{[6]}$ Notably, photoresponsive oxazoline-Cu complexes, ${ }^{[7]} \mathrm{NHC}$ ligands ${ }^{[8]}$ and a number of organocatalysts ${ }^{[9]}$ have been investigated, by targeting product control, ON/OFF switch of the catalytic activity and enantioselectivity tuning. However, studies on photoswitchable phosphines and their catalytic uses have been rarely disclosed so far, despite the key role of phosphines in both organometallic and organocatalysis.

This short review intends to survey the current knowledge in this overlooked field, so as to hopefully stimulate more extended future developments. This paper will summarize the main synthetic approaches to photoresponsive phosphines and their metal complexes, as well as the known examples of catalytic switches. A non-catalytic use of photoswitchable phosphines in organic synthesis is also illustrated.

\section{Synthesis of photoswitchable phosphines}

Synthetic strategies toward photoresponsive phosphines rest on three well-known photochromic moieties, namely azobenzenes, dithienylethenes and 1,1'-biindanes (Scheme 1), to which phosphorus functions can be appended easily.

Azobenzenes are known to toggle between E- and metastable Z-forms under irradiation with UV light, while the reverse process takes place either thermally (T-type chromophores) or under irradiation with visible light. ${ }^{[10]}$ Dithienylethenes, typified in Scheme 1 by dithienylcyclopentenes, are P-type chromophores undergoing conrotatory ring-closure / ring opening reactions under irradiation at different wavelengths. ${ }^{[11]}$

(a)

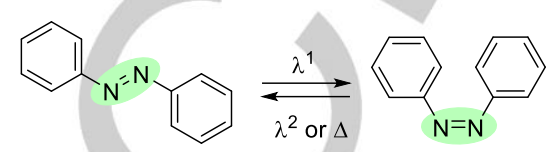

(b)

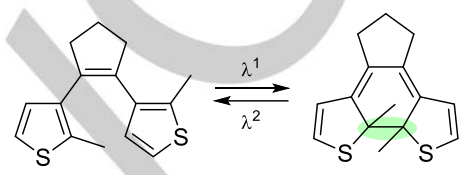

(c)
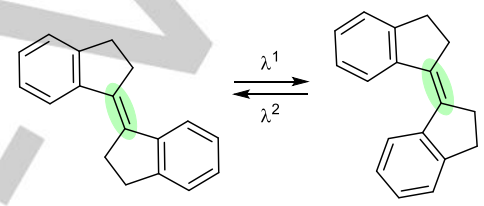

Scheme 1. Structural units for the engineering of photoresponsive trivalent phosphines: (a) azobenzenes, (b) dithienylethenes, (c) biindanes.

Finally, 1,1'-biindanes belong to the family of overcrowded alkenes $^{[12]}$ that alternate between $\mathrm{E}$ and $\mathrm{Z}$ isomeric forms when irradiated in the UV and visible range respectively (P-type chromophores).

The synthetic approaches to phosphines based on these three photoswitchable backbones are typified hereafter.

\subsection{Azobenzene derived phosphines}

Phosphines displaying azobenzene units are easily available by either forming the azo linkage from suitably functionalized arylphosphines or by late introduction of phosphorus on preformed azobenzenes.

In the late nineties, K.R. Flower first demonstrated that the aromatic electrophilic substitutions of arenediazonium tetrafluoroborates on naphthols or phenols tolerate trivalent phosphine and phosphine sulfide functions, allowing the synthesis of the azobenzene-phosphine derivatives 1-3 in Scheme 2[13] 


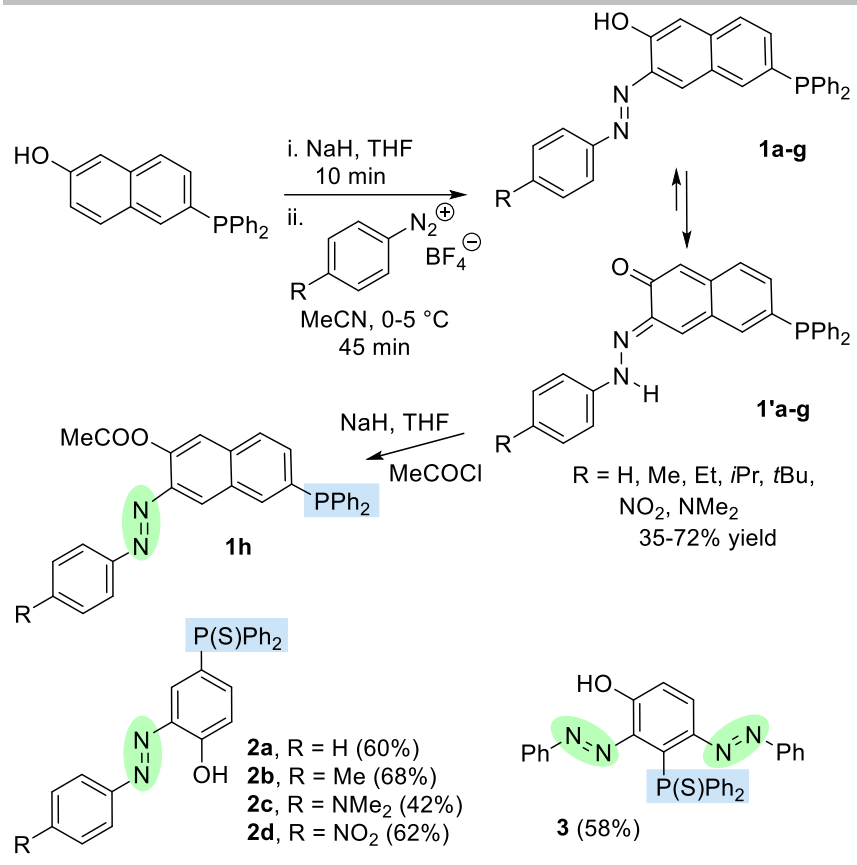

Scheme 2. Synthesis of azobenzene-phosphines and phosphine sulfides from arenediazonium salts by electrophilic aromatic substitutions on naphthols or phenols

The regioselectivity of these reactions is controlled by the ortho/para-directing effects of the $\mathrm{OH}$ functions of the substrates. Phosphines 1a-g formally display an azo linkage, but exist primarily as the hydrazone tautomers 1 '. Tautomerization can be prevented by $\mathrm{O}$-acylation that leads thus to defined azobenzene moieties (1h).

Alternatively, the azo-linkage can be created through dehydrative condensation of aminoaryl-phosphines with appropriate nitrosobenzenes (Mills reaction). As illustrated in Scheme 3, the method has been applied to the synthesis of the first axially chiral azobenzene-phosphine (S)-4 that displays a binaphthyl core. ${ }^{[14]}$

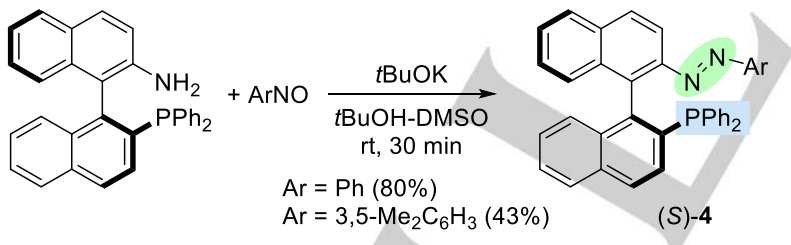

Scheme 3. Condensation of an amino-phosphine with nitrosoaryls

Beyond the few examples above, the most general synthetic method remains the introduction of phosphorus functions on preformed iodo- or bromo-azobenzenes, via either a halogenlithium exchange / phosphination sequence, or by palladiumpromoted couplings with secondary phosphines.

The lithiation-phosphination method has been used initially for the synthesis of the amino-substituted monophosphine $5 \mathrm{a}$ (Scheme 4a), with the purpose to investigate the nonlinear optical properties of the corresponding oxides, e.g. $\mathbf{5 b}$, and phosphonium salts. ${ }^{[15]} \quad$ Later, the parent monophosphine, $p$ $\mathrm{Ph}_{2} \mathrm{P}-\mathrm{C}_{6} \mathrm{H}_{4}-\mathrm{N}=\mathrm{N}-\mathrm{C}_{6} \mathrm{H}_{5} 6 \mathbf{6},{ }^{[16]}$ and the mono- and diphosphines 7 and 8, with fluoro-substituted azobenzene units, have been obtained in good yields by the same method (Scheme 4b). In the last two examples, the lithiation step must be carried out at very low temperature $\left(-95^{\circ} \mathrm{C}\right.$ to $\left.-130^{\circ} \mathrm{C}\right)$ to reach good yields. ${ }^{[17]}$ Also, phosphines 9a-c that display three azobenzene units on phosphorus have been prepared by halogen-lithium exchange, followed by reaction with $\mathrm{PCl}_{3}$ (Scheme 4c), ${ }^{[15 c]}\left[{ }^{[18]}\right.$

(a)

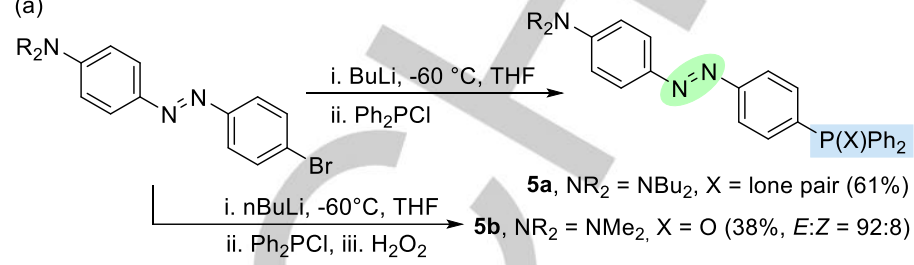

(b)

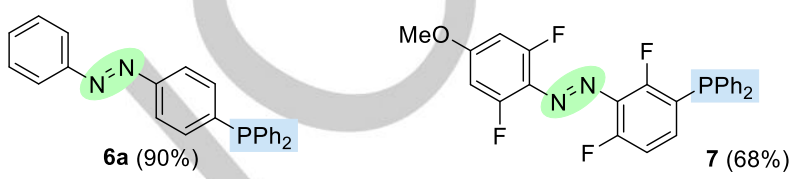

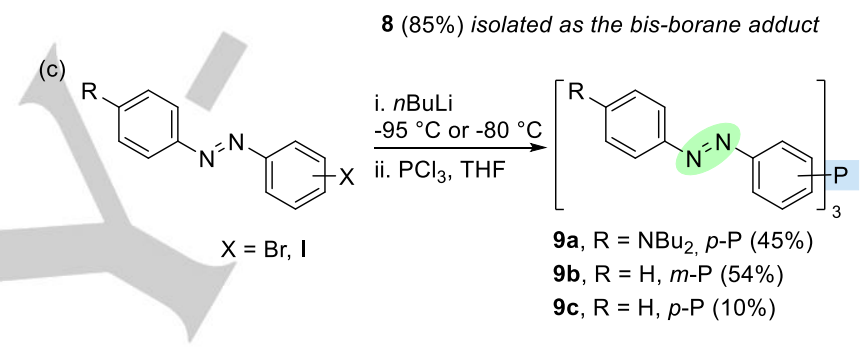

Scheme 4. Synthesis by lithiation/phosphination of iodo- or bromoazobenzenes

Alternatively, lithiated azobenzenes have been reacted with $\mathrm{CIP}(\mathrm{S}) \mathrm{Ph}_{2}$ and the corresponding phosphines $\mathbf{1 0}$ have been obtained then by desulfuration with tributylphosphine (Scheme $5 .^{[19]}$

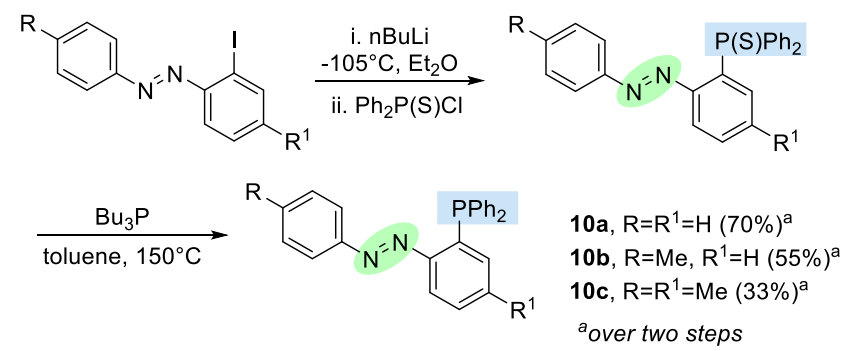

Scheme 5. Two-step synthesis from lithiated azobenzenes and $\mathrm{Ph}_{2} \mathrm{P}(\mathrm{S}) \mathrm{Cl}$

Palladium(II)-promoted couplings of iodo-azobenzenes with secondary phosphines $\left(\mathrm{Ar}_{2} \mathrm{PH}\right)$ are typified in Scheme 6 by the synthesis of phosphines bearing hydroxyl (or alkoxy) and sulfonate functions, reported by Corriu ${ }^{[20]}$ and Monflier ${ }^{[21]}$ respectively (Scheme 6a-b). These reactions were performed by heating the substrates mixtures at $100-135^{\circ} \mathrm{C}$ in the presence of $\mathrm{Pd}(\mathrm{OAc})_{2}$ 
The same strategy and analogous conditions allowed the synthesis of the ester-functionalized phosphines $1^{[22]}$ and the parent para- and meta-phosphines $\mathbf{6 a}$ and $14 \mathrm{a}^{[18 \mathrm{a}]}$ (Scheme 6c).

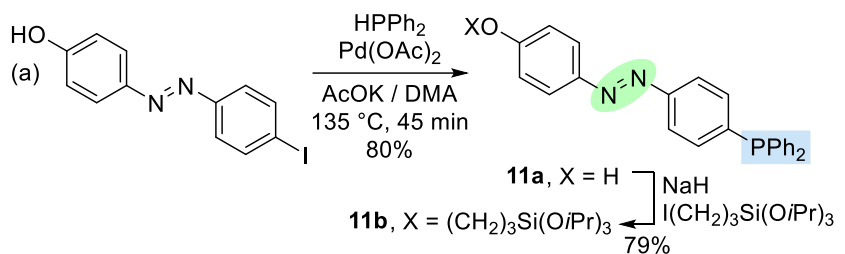

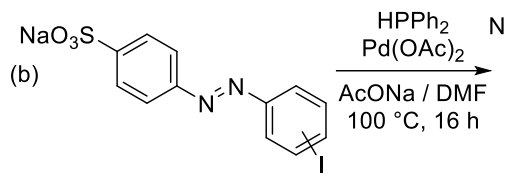<smiles>[R]c1ccc(N=Nc2ccc(C(C)=O)c(P)c2)cc1</smiles>

13a, $\mathrm{R}=\mathrm{H}(74 \%)$

13b, $\mathrm{R}=\mathrm{NEt}_{2}(63 \%)$

13c, $\mathrm{R}=\mathrm{O}\left(\mathrm{CH}_{2} \mathrm{CH}_{2} \mathrm{O}\right)_{3} \mathrm{Me}(85 \%)$ increase of the $440 \mathrm{~nm}$ band characteristic of the Z-isomer $\left(\mathrm{n} \rightarrow \pi^{*}\right.$ transition). After $1 \mathrm{~h}$ an approximately $1: 4 \quad E: Z$ mixture was obtained. The thermal back $Z \rightarrow E$ isomerization proved to be slow, a $\sim 1: 1$ ratio of the two isomers $6 \mathbf{a} / \mathbf{6} \mathbf{a}^{\prime}$ being observed after $38 \mathrm{~h}$ in the dark at $25^{\circ} \mathrm{C}$. ${ }^{18 \mathrm{a}]}$

An analogous behavior has been observed for the o-phosphine $10 \mathrm{~b}$ that displays a $p$-tolyl group $(\mathrm{R}=\mathrm{Me})$ on the diazo unit (Scheme 7a). However, the unsubstituted o-phosphine 10a (Scheme 7b) does not undergo photoisomerization under analogous conditions. This phosphine is locked indeed in its Eform as a result of the equilibrium between the trivalent form and the inner phosphonium salt form (Scheme 7b, right). ${ }^{[19 a]}$ As far as we know, this is the only example in which photoisomerization of a trivalent azobenzene-phosphine does not proceed.

\subsection{Dithienylcyclopentene derived mono- and diphosphines}

Besides azobenzenes, the most widely studied photochromic backbones are 1,2-dithienylethenes (DTE). They are P-type chromophores that interconvert reversibly between "ringopened" and "ring-closed" forms by light induced C-C bond formation/cleavage (Scheme 1b). Compounds of this class generally display good thermal stability of both forms and tolerate a large number of switching cycles (high fatigue resistance). Furthermore, the two isomers have markedly different three-dimensional geometries, conformational freedom and physicochemical properties.

These few examples show that, despite the rather harsh conditions, the method tolerates the diazo unit as well as the presence of functional groups. It tolerates also a degree of steric hindrance, since the ortho-substituted phosphines 13 could be obtained in good yields.

The photochemical behavior of azobenzene-derived phosphines is illustrated in Scheme 7 by the E/Z reversible isomerization of phosphines $6 a$ and 10b.[18a, 19a] These reactions have been monitored by UV-vis and ${ }^{31} \mathrm{P}$ NMR spectroscopy.

(a)

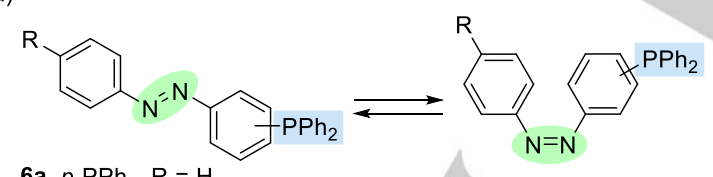

6a, $p-\mathrm{PPh}_{2}, \mathrm{R}=\mathrm{H}$

10b, $\mathrm{o}-\mathrm{PPh}_{2}, \mathrm{R}=\mathrm{Me}$

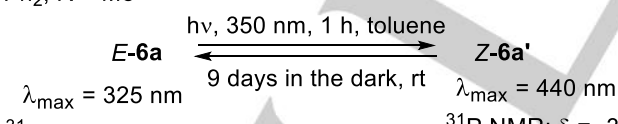

$$
\begin{aligned}
& { }^{31} \mathrm{P} \text { NMR: } \delta=-1.9 \quad{ }^{31} \mathrm{P} \text { NMR: } \delta=-3.8
\end{aligned}
$$

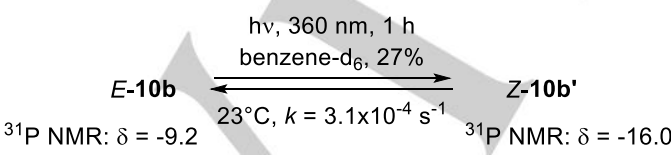

(b)

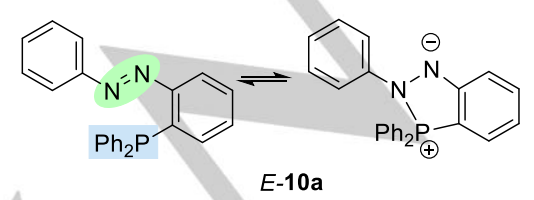

Scheme 7. Representative photoswitch of azobenzene-derived phosphines

Thus, when a toluene solution of E-6a was irradiated at $350 \mathrm{~nm}$ in toluene, UV monitoring showed a decrease of the $325 \mathrm{~nm}$ band typical of the E-isomer ( $\pi \rightarrow \pi^{*}$ transition), with concomitant
In 2005, Branda disclosed the first examples of trivalent phosphines displaying a dithienylethene backbone. ${ }^{[23]}$ Starting from 1,2-bis-(5'-chloro-2'-methylthienyl)perfluoro-cyclopentene, an halogen-lithium exchange and subsequent reaction with $\mathrm{Ph}_{2} \mathrm{PCl}$, led to diphosphine 15. The phosphorus functions are attached to positions 5 ' of the two thiophene units (Scheme $8 \mathrm{a}$ ).
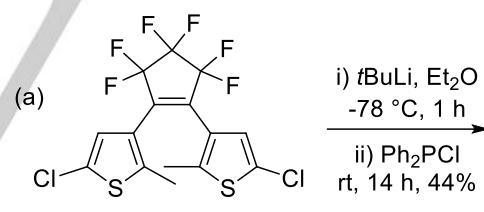

(b)

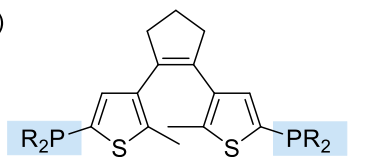

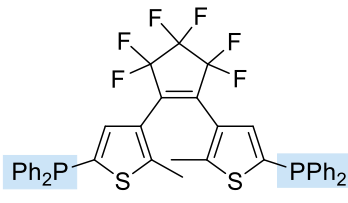

15

$$
\begin{aligned}
& 16 a, R=P h \\
& 16 b, R=C y
\end{aligned}
$$

Later on, Liu ${ }^{[24]}$ applied the same method to the synthesis of the related $C_{2}$-symmetric diphosphines $16 \mathbf{a}, \mathbf{b}$ (Scheme $8 \mathrm{~b}$ ) from a non-fluorinated dithienylcyclopentene dichloride. The corresponding oxides, sulfides and selenides have been described as well.

The photocyclizations of fluorinated and non-fluorinated phosphines of this series have been investigated independently (Scheme 9). Diphosphine 15 undergoes ring closure under irradiation at $313 \mathrm{~nm}$ in $\mathrm{CH}_{2} \mathrm{Cl}_{2}$, giving a 20:80 ratio of the two isomers at the photostationary state. ${ }^{[23]}$ The solution changed from colorless to deep purple, since the closed isomer 15 ' shows an absorption band at $\lambda_{\max }=570 \mathrm{~nm}$. The reverse ringopening process occurred under irradiation at $\lambda>434 \mathrm{~nm}$. Most 
noteworthy, the photoisomerization cycle could be performed several times without significant degradation. To get insights on the effects of the photoisomerization on the electronic properties of $15 / 15$ ', the authors measured ${ }^{1} J\left({ }^{77} \mathrm{Se}-{ }^{31} \mathrm{P}\right)$ coupling constants in the corresponding bis-selenides. The results showed that the open form of the phosphine $\left({ }^{1} \mathrm{~J}_{\mathrm{P}-\mathrm{Se}}=744 \mathrm{~Hz}\right)$ is significantly more electron-rich than the corresponding closed isomer $\left({ }^{1} \mathrm{JP}_{\mathrm{P}-\mathrm{Se}_{\mathrm{e}}}=756\right.$ $\mathrm{Hz})$.
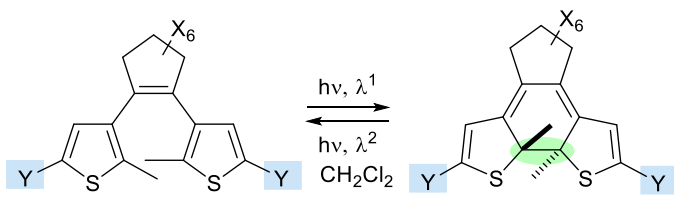

$15-17$

$15^{\prime}-17^{\prime}$

\begin{tabular}{|c|c|c|c|c|c|c|c|}
\hline Comp & $\mathrm{X}$ & $\mathrm{Y}$ & $\begin{array}{c}{ }^{31} \mathrm{P} \mathrm{NMR} \\
\delta(\mathrm{ppm}), J(\mathrm{~Hz})\end{array}$ & $\lambda^{1}$ & $\lambda^{2}$ & PSS & Ref \\
\hline $\mathbf{1 5 / 1 5}$ & $\mathrm{F}$ & $\mathrm{PPh}_{2}$ & $-18.7 /-8.3$ & 313 & $>434$ & $20: 80^{\mathrm{c}}$ & ${ }^{[23]}$ \\
\hline $\mathbf{1 7}$ & $\mathrm{F}$ & $\mathrm{P}(\mathrm{Se}) \mathrm{Ph}_{2}$ & $\begin{array}{c}22.4 / 27.0 \\
J_{P-S e}=744 / 756\end{array}$ & 313 & $>434$ & $45: 55^{\mathrm{c}}$ & ${ }^{[23]}$ \\
\hline $\mathbf{1 6 a / 1 6 a}$ & $\mathrm{H}$ & $\mathrm{PPh}_{2}$ & -20.0 & $254^{\mathrm{a}}$ & $510^{\mathrm{b}}$ & $70: 30^{\mathrm{d}}$ & ${ }^{[24]}$ \\
\hline $\mathbf{1 6 b} / \mathbf{1 6 b}$ & $\mathrm{H}$ & $\mathrm{PCy}_{2}$ & -9.1 & 254 & 510 & $73: 27^{\mathrm{d}}$ & ${ }^{[24]}$ \\
\hline
\end{tabular}

${ }^{\text {a }}$ Quantum yield $\Phi=0.14 ;{ }^{\mathrm{b}} \Phi=0.84 ;{ }^{\mathrm{c}}$ Ratio determined by ${ }^{1} \mathrm{H}$ NMR; ${ }^{\mathrm{d}}$ Ratio determined by HPLC

Scheme 9. Photoisomerization of dithienylcyclopentene-derived diphosphines and phosphine selenide.

The non-fluorinated dithienylethene diphosphines $16 \mathrm{a}, \mathrm{b}$ gave cyclization/ring opening reactions under irradiation at $254 \mathrm{~nm}$ and $510 \mathrm{~nm}$ respectively. The UV-vis spectra of the open forms 16a,b $\left(Y=\mathrm{PPh}_{2}\right.$ and $\left.\mathrm{Y}=\mathrm{PCy} \mathrm{y}_{2}\right)$ show absorption bands at $\lambda_{\max }=228$ and $233 \mathrm{~nm}$, while the red-colored closed forms 16a',b' display red-shifted absorption bands at 505 and $497 \mathrm{~nm}$ respectively. Thus, compared to diphosphine 15', the nonfluorinated diphosphines 16a',b' display the red-shifted absorption bands at significantly lower wavelengths $(\Delta \delta=-65 \mathrm{~nm})$

In 2015, Wass, Scarso et al. ${ }^{[25]}$ have reported on two series of mono-phosphines, 18a-c and 19a-c, with fluorinated and nonfluorinated dithienylcyclopentene backbones respectively. These compounds feature chlorine, phenyl and anisyl substituents on the second thiophene unit (Scheme 10)

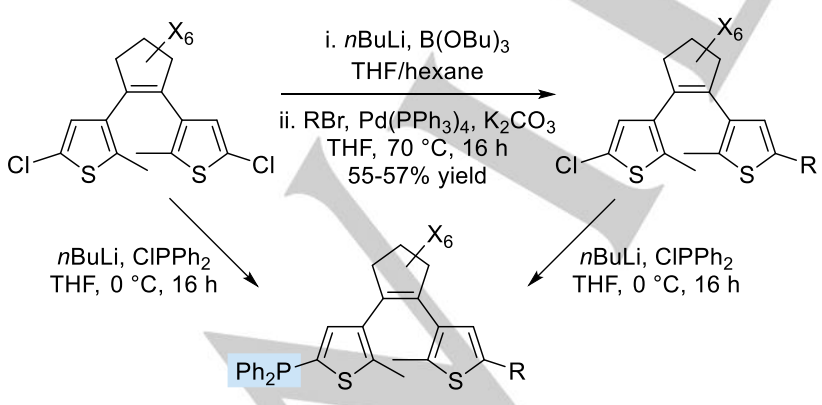

$$
\begin{array}{cc}
18 a, X=F, R=C l(42 \%) & 19 a, X=H, R=C l(48 \%) \\
18 b, X=F, R=P h(63 \%) & 19 b, X=H, R=P h(63 \%) \\
18 c, X=F, R=4-M e O-C_{6} H_{4}(60 \%) & 19 c, X=H, R=4-M e O-C_{6} H_{4}(64 \%) \\
\quad \delta{ }^{31} \mathrm{P}=-20.9 p p m & \quad \delta{ }^{31} \mathrm{P}=-18.9 p p m
\end{array}
$$

These compounds were obtained from the corresponding thienyl chlorides by a lithiation/phosphination sequence. The ${ }^{31} \mathrm{P}$ NMR spectra of the corresponding selenides showed that phosphines with fluorinated backbones have lower electron-donating ability (e.g. ${ }^{1} \mathrm{JP}_{\mathrm{P} S \mathrm{Se}}=744 \mathrm{~Hz}$ for $18 \mathrm{c}$ vs $737 \mathrm{~Hz}$ for $19 \mathrm{c}$ ), while the nature of the $R$ substituent on the remote thiophene unit does not make substantial difference.

The photoinduced cyclisations took place under UV irradiation at $365 \mathrm{~nm}$ for the aryl-substituted compounds 18b,c and 19b,c ( $R=$ aryls), while the chloro-substituted phosphines $18 a$ and 19a were irradiated at $310 \mathrm{~nm}$ to generate their closed forms. The reverse ring-opening reaction took place under irradiation at $\lambda>$ $600 \mathrm{~nm}$.

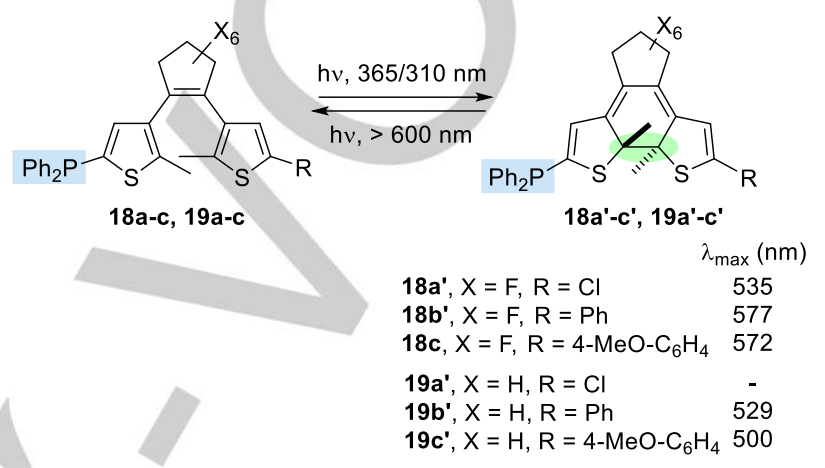

Scheme 11. Photocyclisation conditions and absorption maxima of the closed forms 18' and 19'

The absorption wavelengths of the cyclized isomers 18' and 19' in the visible region are highly dependent on their respective substitution patterns (Scheme 11). Thus, solutions of 18b' and 18c' are blue-colored, while 19b' and 19c' give red solutions and 19a' a yellow-orange one. This last compound showed an increased absorption in the range $450-300 \mathrm{~nm}$, but did not display defined $\lambda_{\max }$ values.

In this series also, ring closure decreases the $\sigma$-donating ability of the phosphines, as shown by the increased ${ }^{1} \mathrm{~J}_{\mathrm{P} \text {-Se }}$ coupling constants in the corresponding selenides after cyclization (e.g. ${ }^{1} \mathrm{JP}_{\mathrm{P} S \mathrm{Se}}=742 \mathrm{~Hz}$ for $18 \mathrm{a}$ and ${ }^{1} \mathrm{JP}_{\mathrm{P}-\mathrm{Se}}=757 \mathrm{~Hz}$ for $18 \mathrm{a}$ '; ${ }^{1} \mathrm{JP}$-Se $=737$ $\mathrm{Hz}$ for $19 \mathrm{a}$ and ${ }^{1} \mathrm{JP}_{\mathrm{P} S \mathrm{Se}}=747 \mathrm{~Hz}$ for $19 \mathrm{a}$ ').

\subsection{Biindane derived diphosphines}

Only three recent literature reports relate to the synthesis of biindane-derived phosphines from suitably functionalized biindanes.

In 2014, Widenhoefer, Boulatov and Craig have prepared the macrocyclic diphosphine $\mathbf{2 1}$ by O-alkylation of the $(S)$ diphosphine 20, using a biindane-derived bis-mesylate (Scheme 12). ${ }^{[26]}$ 
<smiles>COCCCOc1ccc2c(c1)/C(=C1/CCc3ccc(OCCCOC)cc31)CC2</smiles>
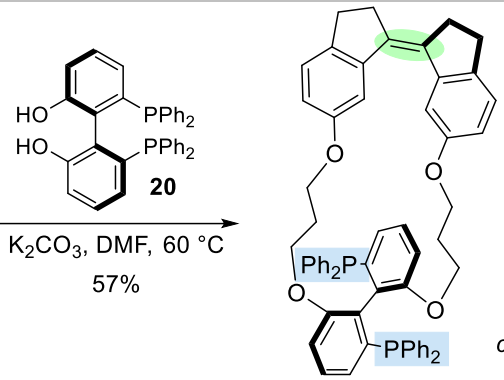

cis-21

Scheme 12. Synthesis of a biindane-derived macrocyclic diphosphine.

The diphosphine has been used then as chiral ligand in palladium-promoted Heck reactions that will be discussed in section 4.3.1 hereafter.

The two other reports on biindane-derived diphosphines are from the Feringa group. In 2015, the group disclosed the synthesis of diphosphines trans-23 and trans-25 in which amide functions connect a biindane scaffold to diphenylphosphino-aryl groups (Scheme 13). ${ }^{[27]}$ The phosphorus function of trans-23 has been introduced by amidation of the enantioenriched biindanecarboxylic acid trans-22 with ortho-diphenylphosphino-aniline. The photochemical and thermal isomerization of trans-23 will be discussed later in the context of its uses in catalysis (see $\S$ 4.3.2).
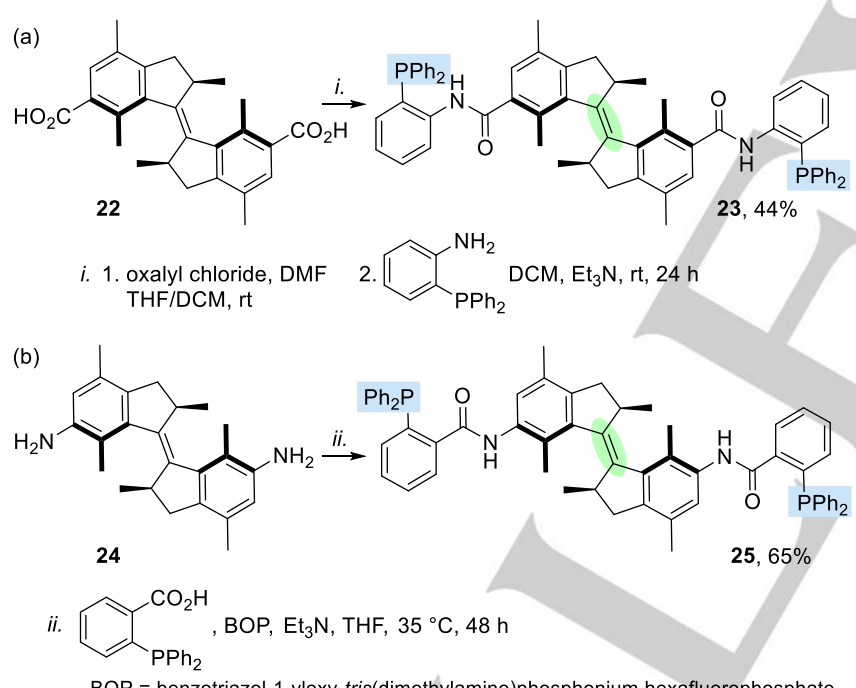

Scheme 13. Synthesis of biindane-based diphosphines
On the other hand, the optically pure amino-biindane trans-24${ }^{[28]}$ has been converted into diphosphine trans-25 by coupling with ortho-diphenylphosphino-benzoic acid in the presence of BOP. The isomerization of trans-25 under irradiation at $312 \mathrm{~nm}\left(-15^{\circ} \mathrm{C}\right.$ in THF) led to only $7 \%$ conversion into the corresponding cisisomer and, therefore, this phosphine was not investigated further.

Finally, in 2020, B. L. Feringa reported on the synthesis of the parent Z- and E-biindane-derived diphosphines 26 and 26' via a palladium-promoted coupling of the corresponding 6.6'diiodobiindanes with $\mathrm{Ph}_{2} \mathrm{PH} .{ }^{[29]}$

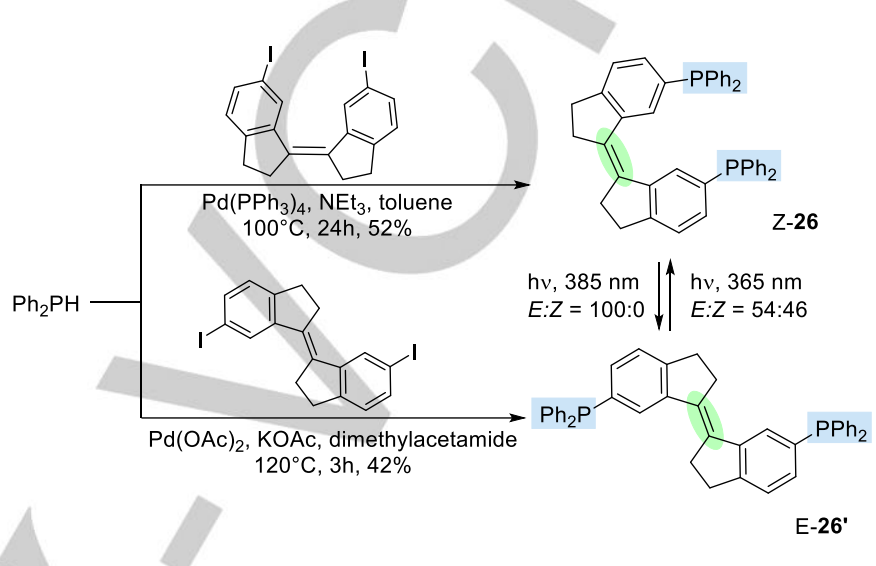

Scheme 14. Synthesis of the biindane derived diphosphines 26 and 26' via Pd-promoted phosphinations.

The two compounds have distinct absorption spectra with $\lambda_{\max }=$ $356 \mathrm{~nm}$ for $Z-26$ and $\lambda_{\max }=338$ and $356 \mathrm{~nm}$ for $E-26$ '. $Z \rightarrow E$ conversion takes place quantitatively under irradiation at $385 \mathrm{~nm}$ and the reverse $\mathrm{E} \rightarrow Z$ reaction under irradiation in benzene at $365 \mathrm{~nm}$ ( $E / Z 54 / 46$ mixture at the photostationary state).

${ }^{31} \mathrm{P}$ NMR experiments on the corresponding selenides demonstrate that the donor properties of phosphorus are almost identical for the two isomers $\left({ }^{1} \mathrm{~J}_{\mathrm{P}-\mathrm{Se}}=364 \mathrm{~Hz}\right)$

\section{Transition metal complexes}

\subsection{Complexation of preformed phosphines}

Most commonly, transition metal complexes of azobenzeneDTE- and biindane derived phosphines are obtained by coordination of the preformed phosphine to a suitable metal precursor. The known examples of metal complexes obtained by this method are listed in Table 1. 
Table 1. Transition metal complexes obtained from preformed phosphines

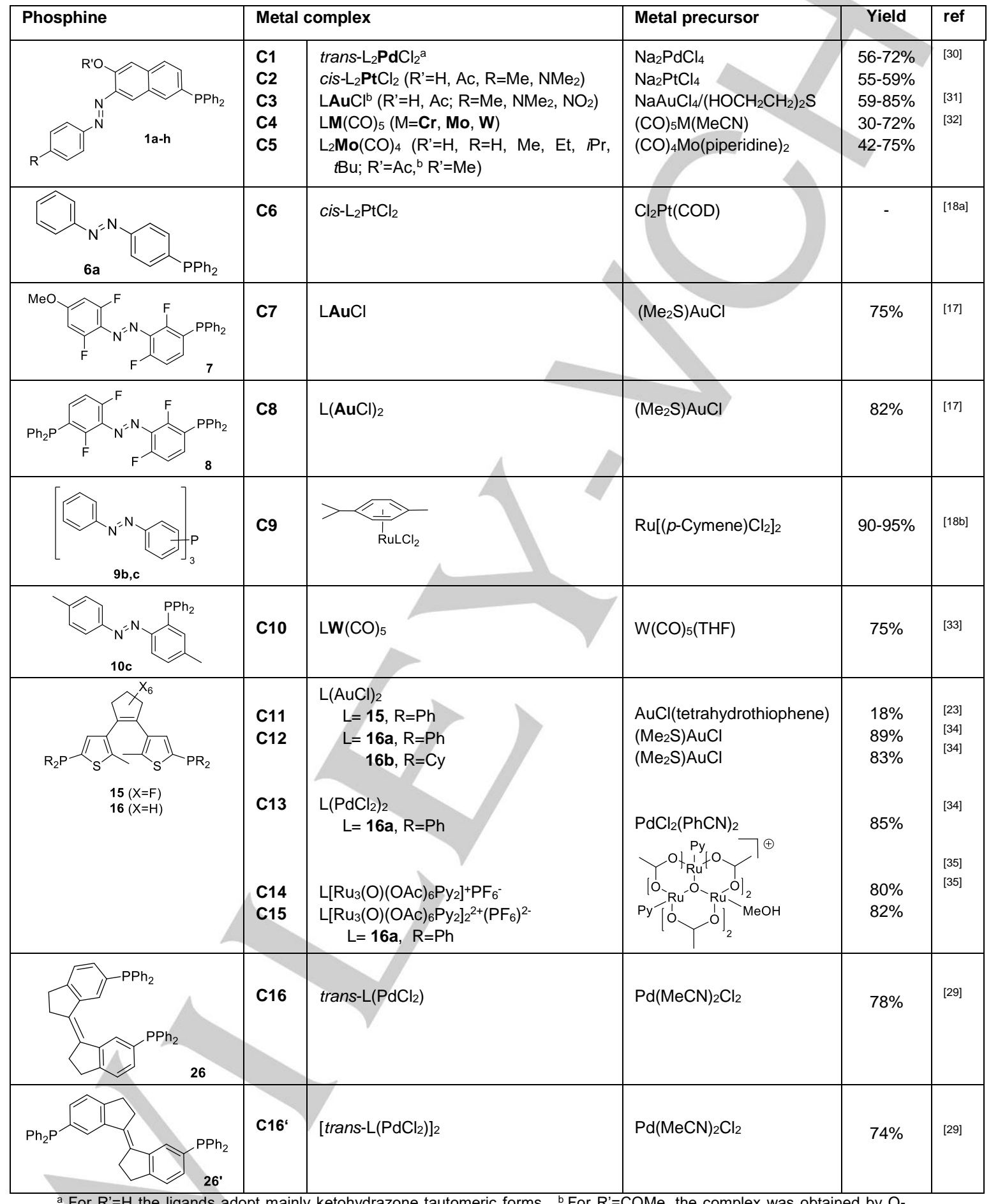

${ }^{a}$ For $\mathrm{R}^{\prime}=\mathrm{H}$ the ligands adopt mainly ketohydrazone tautomeric forms. ${ }^{\mathrm{b}}$ For $\mathrm{R}$ '=COMe, the complex was obtained by $\mathrm{O}$ acylation of the corresponding $\mathrm{OH}$-functionalized $\mathrm{L}_{2} \mathrm{Mo}(\mathrm{CO})_{4}$ complex.

\section{Azobenzenes}

For all the examples of azobenzene derivatives quoted in the Table, coordination of phosphorus to a transition metal takes place under standard conditions and does not induce major structural changes of the ligands. A divergent behaviour has been reported for ligand $E-10 \mathrm{c}$ in its reaction with $\mathrm{PtCl}_{2}$ (cod). In this case, the reaction leads to the platinacyclic species $\mathbf{C 1 7}$ by concomitant coordination of phosphorus and nitrogen and metalation of the aryl ring. ${ }^{[33]}$ 
<smiles>Cc1ccc(N=Nc2ccc(C)cc2-c2ccccc2)cc1</smiles>

$E-10 c$

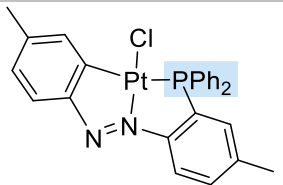

C17

${ }^{31} \mathrm{P}: \delta=30.2\left({ }^{1} \mathrm{~J}_{\mathrm{Pt}-\mathrm{P}}=2072 \mathrm{~Hz}\right)$
Scheme 15. An example of platinacyclic complex

The molecular structure of the final product has been ascertained by $\mathrm{X}$-ray diffraction studies.

In most instances, in the azobenzene series, coordination does not influence significantly neither the $\mathrm{E} \rightarrow Z$ photoisomerization nor the reverse thermal process. Thus, coordination of $E-6 \mathbf{a}$ to $\mathrm{Pt}(\mathrm{II})$, generates the cis- $(E-6 \mathbf{a})_{2} \mathrm{PtCl}_{2}$ complex $\mathbf{C 6}$ that undergoes $\mathrm{E} \rightarrow Z$ isomerization under irradiation at $350 \mathrm{~nm}$ in toluene for $1 \mathrm{~h}$. The resulting mixture contains the $\left(\mathbf{Z}-\mathbf{6} \mathbf{a}^{\prime}\right)_{2} \mathrm{PtCl}_{2}$ complex $\mathbf{C} \mathbf{6}^{\prime}$ and a complex featuring both an $E$ - and a $Z$-ligand, together with traces of the starting material $\mathbf{C 6}$. The mixture undergoes slow back isomerization in the dark at room temperature (Scheme $16)^{[18 a]}$
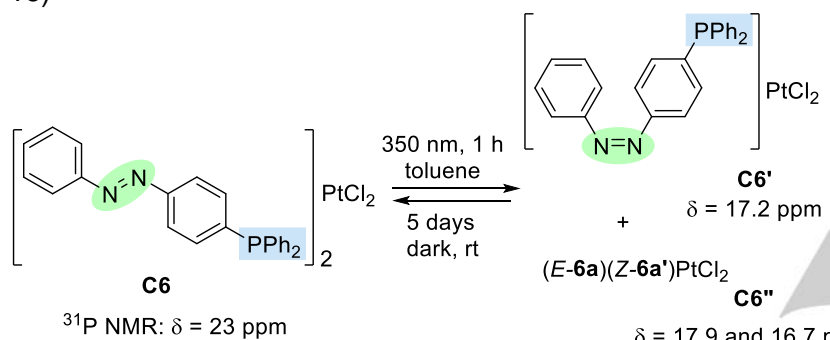

$(E-6 \mathbf{a})\left(Z-6 \mathbf{a}^{\prime}\right) \mathrm{PtCl}_{2}$

$$
\delta=17.9 \text { and } 16.7 \mathrm{ppm}
$$
$J_{\mathrm{PP}}=15.8 \mathrm{~Hz}$

Scheme 16. Photoisomerization of the platinum(II) complex C6

The same holds for the ( $p$-cymene) $\mathrm{Ru}(9) \mathrm{Cl}_{2}$ complex c9 displayed in Table 1: the half-life time of the Z-isomer is roughly identical to that of the corresponding phosphine $9 \mathrm{c}$ (115 $\mathrm{min}$ at $\left.55^{\circ} \mathrm{C}\right) \cdot{ }^{[18 \mathrm{~b}]}$

\section{Dithienylcyclopentenes}

Concerning dithienylcyclopentene based diphosphines, coordination to gold, ${ }^{[23,34,36]}$ palladium $^{[34]}$ and ruthenium ${ }^{[35]}$ has been reported. The bis-gold complexes $\mathbf{C 1 1}, \mathbf{C 1 2 a}$ and $\mathbf{C 1 2 b}$ that contain diphosphines $15\left(\mathrm{X}=\mathrm{F}, \mathrm{PR}_{2}=\mathrm{PCy}_{2}\right), 16 \mathrm{a}$ and $16 \mathrm{~b}$ $\left(\mathrm{X}=\mathrm{H}, \mathrm{PR}_{2}=\mathrm{PPh}_{2}\right.$ and $\left.\mathrm{PCy}_{2}\right)$ respectively, undergo reversible conversion between ring-opened and ring-closed isomers under irradiation with $302 \mathrm{~nm}$ UV light and $>400 \mathrm{~nm}$ visible light.

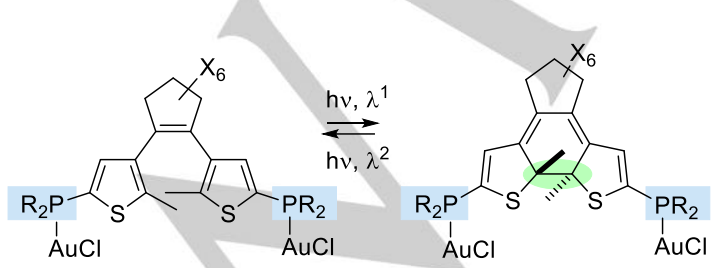

$$
\text { C11 / C12 C11'/C12' }
$$

\begin{tabular}{|c|c|c|c||c|c||c|c||c|}
\hline Comp & $\mathrm{X}$ & $\mathrm{PR}_{2}$ & $\lambda_{\max }$ & Comp & $\lambda_{\max }$ & $\lambda^{1}$ & $\lambda^{2}$ & Ref \\
\hline C11 & $\mathrm{F}$ & $\mathrm{PPh}_{2}$ & - & $\mathbf{C 1 1}^{4}$ & 565 & 313 & $>434^{\mathrm{a}}$ & {$[23]$} \\
\hline C12a & $\mathrm{H}$ & $\mathrm{PPh}_{2}$ & 229 & $\mathbf{C 1 2 a}^{6}$ & 517 & 302 & $>400$ & {$[34]$} \\
\hline C12b & $\mathrm{H}$ & $\mathrm{PCy}_{2}$ & 232 & $\mathbf{C 1 2 b}^{\mathbf{2}}$ & 503 & 302 & $>400$ & {$[34]$} \\
\hline
\end{tabular}

a The PSS consists in a C11:C11' 40:60 mixture in $\mathrm{CH}_{2} \mathrm{Cl}_{2}$.

Scheme 17. Photoisomerization and absorption maxima for the gold complexes $\mathbf{C 1 1}$ and $\mathbf{C 1 2}$.
The red-colored closed forms C11', C12a' and C12b' have absorption maxima at 565, 517 and $503 \mathrm{~nm}$ respectively, that is slightly blue-shifted for C11' and red-shifted for C12a' and C12b', with respect to the corresponding phosphines $\left(\lambda_{\max }=570,505\right.$ and $497 \mathrm{~nm}$ respectively).

In further studies, the bimetallic gold chloride complex C12a has been converted into a bis-gold-acetylide complex featuring two additional dithienylcyclopentene units (C18, Scheme 18). ${ }^{[36]}$ The aim was to induce multiple photochromic reactions in a single molecule. Thanks to the gold spacers, the two non-equivalent photochromic switches of $\mathbf{C 1 8}$ operate independently. The closed forms are obtained in a stepwise manner, under irradiation at $365 \mathrm{~nm}$ for the $\mathrm{F}_{6}$-cyclopentene units and under irradiation at $254 \mathrm{~nm}$ for the cyclopentene unit.

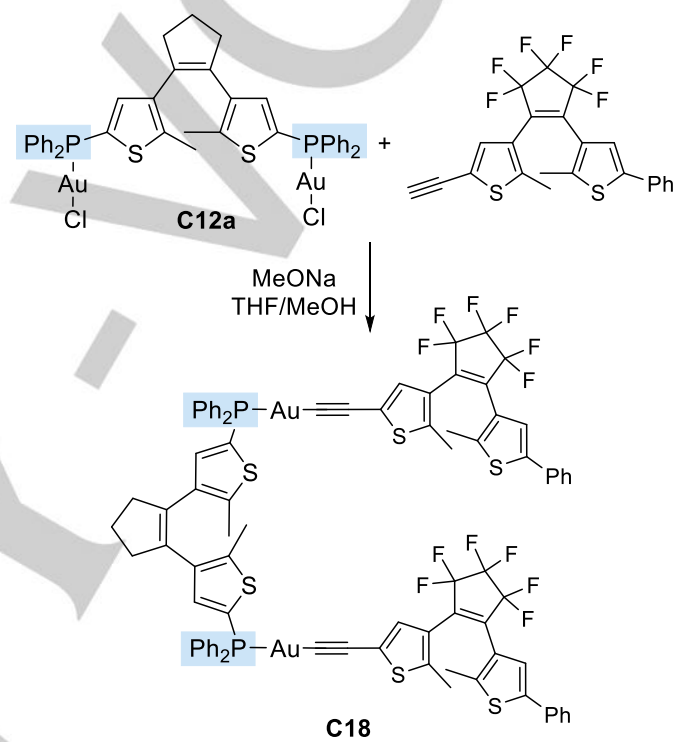

Scheme 18. Synthesis of multi-dithienylethenes from the bimetallic gold complex C12a.

The examples given in Scheme 17, but also analogous studies on ruthenium complexes, ${ }^{[35]}$ suggest that coordination of dithienylethene based phosphines to transition metals does not change significantly the photoswitch process. A notable exception to this general trend has been found with the bimetallic, chloride bridged palladium complex C13 (Scheme 19. ${ }^{[34]}$ This complex does not undergo photoisomerization because of the geometrical constraints of its macrocyclic structure that enforces a long $\mathrm{C}-\mathrm{C}$ distance between the reactive carbons $(4.2 \AA)$. It also enforces a parallel conformation of the two thiophene units, while an anti-parallel orientation is required for the symmetry-allowed conrotatory electrocyclization of the DTE moiety.

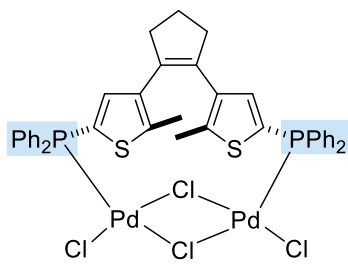

C13

Scheme 19. A non-photoactive palladium complex 
Other studies suggest that the nature and the electronic properties of the ancillary ligands on the metal may also modulate the photoswitch properties of their complexes (see $\S$ 3.2 hereafter).

\section{Biindanes}

In the biindane series, transition metal complexes have been isolated only recently. ${ }^{[29]}$ Diphosphines Z-26 and E-26' have been coordinated to $\mathrm{Pd}(\mathrm{II})$ chloride in separate experiments by reacting the free ligands with $\mathrm{Pd}(\mathrm{MeCN}) \mathrm{Cl}_{2}$.

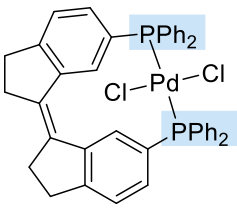

C16

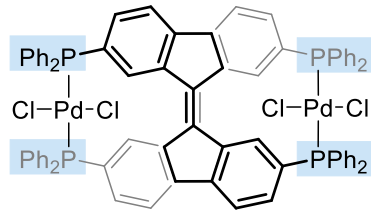

C17
Scheme 20. Mono-and bimetallic Pd(II) complexes of biindane-derived diphosphines.

The Z-isomer of the ligand generated the monometallic transconfigured chelated complex C16, while the E-ligand 26' forms the dimeric complex C17 (Scheme 20). These complexes do not undergo photoisomerization, because of their geometrical constraints.

\subsection{Building of photoswitchable phosphines in the coordination sphere of a metal.}

An alternative to complexation of preformed ligands consists in building the photoswitchable ligands directly in the coordination sphere of the metal. This approach is illustrated in Scheme $21^{[37]}$ by the synthesis of the macrocyclic rhodium(I) complexes C19a,b. These complexes are formed by reacting a diaminoazobenzene with the carboxylic acid functions of the bisphosphine rhodium complexes $27 \mathbf{a}, \mathbf{b}$. The amidation reaction creates a macrocyclic tetradentate ligand that incorporates an azobenzene bridging unit.

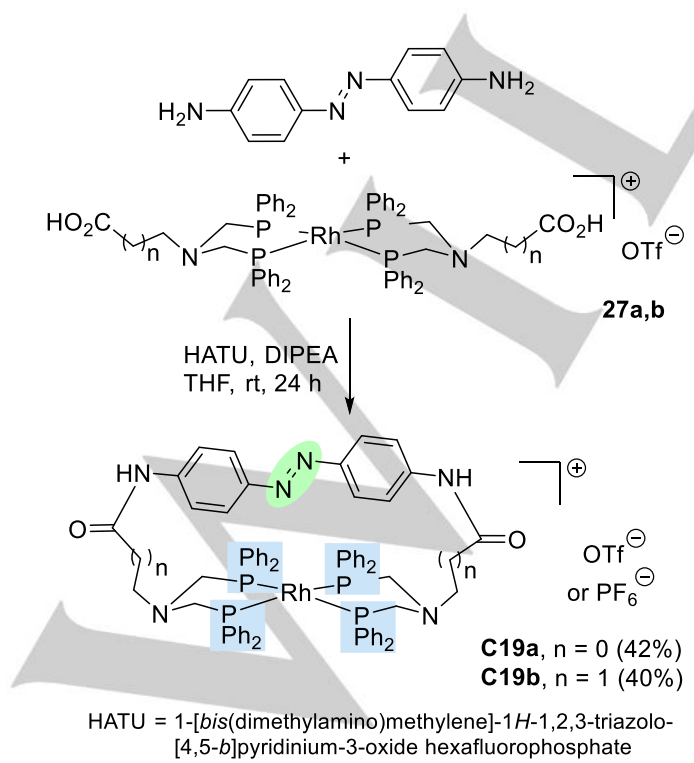

Scheme 21. Synthesis of macrocyclic $\mathrm{Rh}(\mathrm{I})$ complexes.
A second example is the synthesis of the bimetallic copper(I)complex C20, in Scheme 22. ${ }^{[38]}$ The key intermediate is the phosphino-dithienylethene-zirconacycle $\mathbf{2 8}$ that undergoes a zirconium-copper transmetalation, followed by phosphination of the resulting copper intermediate with $\mathrm{Ph}_{2} \mathrm{PCl}$.

It must be noticed that the diphosphine ligands in complex C20 belong to a distinct series of dithienylethene-diphosphines with respect to the previous examples: here, the phosphorus functions are attached to the central olefinic bond, instead of being attached to the thiophene units.

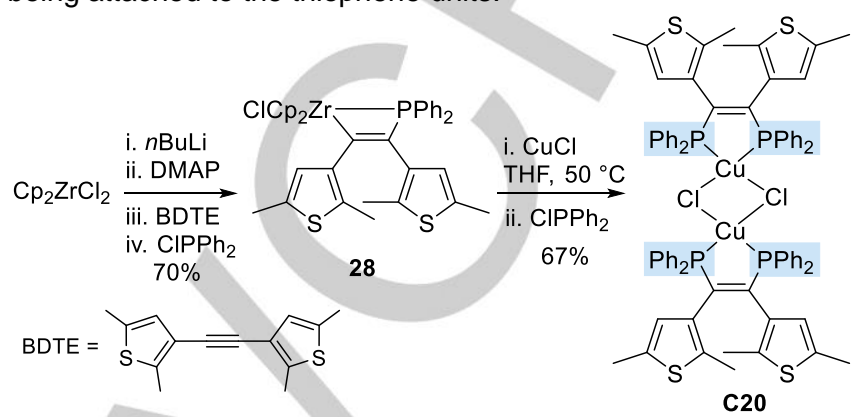

Scheme 22. Synthesis of a copper-complex of DTE-based diphosphines.

Starting from the bimetallic complex $\mathbf{C 2 0}$, ligand exchange reactions gave access to the copper complexes C21 (Scheme 23) that display either phosphorus or nitrogen ligands. This homogeneous series of metal complexes allowed comparative studies of their photochemical behavior. Thus, these studies have highlighted a crucial effect of the ancillary ligands on the ratio between open and cyclized forms at the PSS, under irradiation at $365 \mathrm{~nm}$ (Scheme 23). ${ }^{[38]}$ It has been shown that changing one of the phosphorus ligands in C21a, by either a chloride (as in C22) or a pyridine-type ligand (C21b) decreases the amount of cyclized forms from $51 \%$ to $33 \%$ and $16 \%$ respectively. Moreover, isomerization was totally prevented in C21c that displays a 1,10-phenanthroline as the ancillary ligand.
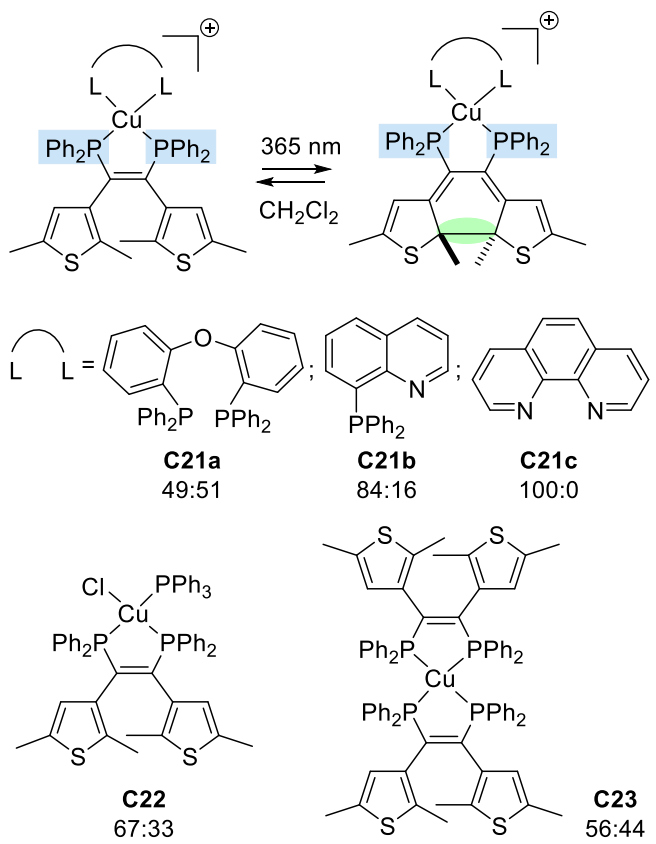

Scheme 23. Photoisomerization of a series of copper complexes of dithienylethene-diphosphines. Ratios of open:closed forms at the photostationary states $(365 \mathrm{~nm})$. 
DFT calculations have suggested that the decreased photoreactivity of the pyridine-ligated complexes C21b and C21c might result from localization of their LUMOs orbitals mainly on the quinoline and 1,10-phenanthroline ligands.

Complex C21a showed photocycloreversion under irradiation at $\lambda>500 \mathrm{~nm}$, with good reversibility after up to eight photochromic cycles.

As a conclusion it can be noticed that, in many instances, coordination of photoswitchable phosphines to transition metals does not change significantly their photoswitch properties. However, in some cases, either geometrical constraints or the electronic effects of ancillary ligands may modulate their photochemical behaviors. To fully enlighten these effects, more extended, systematic studies on homogeneous series are still required.

\section{Catalytic applications}

In the following sections we will summarize literature reports where significant photoswitch effects have been highlighted on the catalytic activity of transition metal complexes bearing photoresponsive phosphines. We do not present here the few additional reports where the effects of photoswitch haven't been mentioned. ${ }^{[14,30,34]}$

\subsection{Catalysts derived from azobenzene based mono- and diphosphines}

\subsubsection{Palladium-promoted decarboxylation of allylic carbonates}

The water soluble, sulfonated azobenzene derived phosphines $E-12 a, b$ undergo isomerization under irradiation at $365 \mathrm{~nm}$, leading to $54: 46$ and $48: 52 E / Z$ mixtures respectively at the photostationary state. The mixtures give back the initial $E / Z$ ratios after one night at room temperature in the dark, or after 10 min under daylight. These phosphines have been used as amphiphilic ligands in the $\mathrm{Pd}(\mathrm{II})$-promoted decarboxylation of allyl undecyl carbonate with diethylamine. The reactions were run both in the dark and under irradiation, and parallel experiments have been conducted with the analogous biphenylphosphine 28, for comparison purposes (Scheme 24). ${ }^{[21]}$

Overall, without UV irradiation, the presence of the diazo function has a detrimental effect on the reaction rate (entries 1,3,5 in Scheme 24). However, upon irradiation (entries 4, 6), the reaction rate increased. Especially, with $\mathbf{1 2 b}$, an increase of the rate by more than 2.5 -folds led to the best turnover frequency in this series $\left(80 \mathrm{~h}^{-1}\right)$.

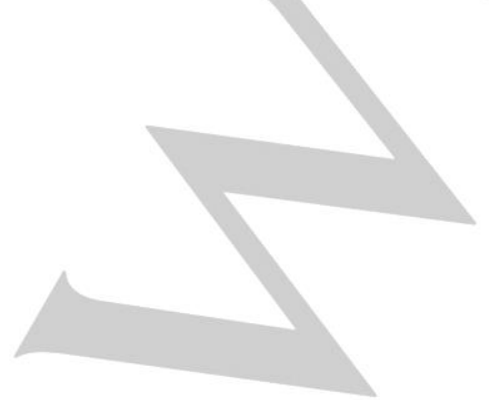

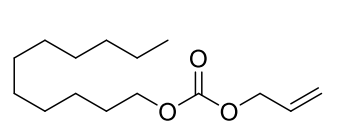

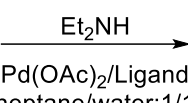
heptane/water: $1 / 1$ $20^{\circ} \mathrm{C}$

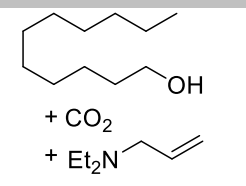

Ligands:

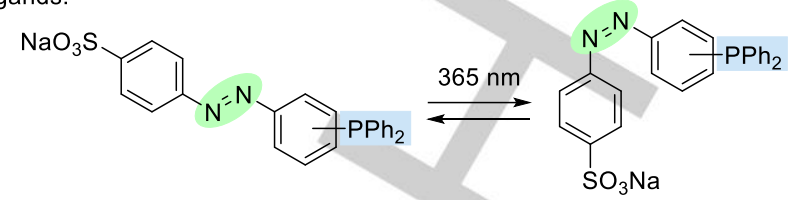

12a, $p$ - $\mathrm{PPh}_{2} ; 91 \%$ E-isomer 12b, $m$-PPh ${ }_{2} ; 95 \%$ E-isomer

hv 90 min: $54: 46 E: Z$ ratio

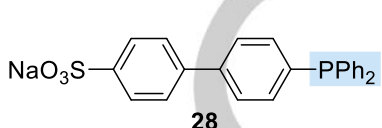

28

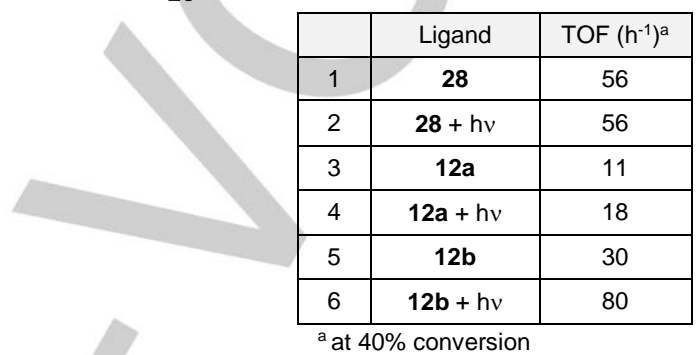

Scheme 24. Palladium-promoted decarboxylation of allylic carbonates

It has been shown that phosphines $12 a$ and $12 b$ form aggregates in water (decreased surface tension). Therefore, the positive effect of the $E \rightarrow Z$ isomerization on the reaction rate has been assigned to the formation of new aggregates that possibly solubilize the substrates in a more efficient way.

These studies have afforded the first example of organometallic catalysis in biphasic media, regulated and stimulated by the in situ photoisomerization of the ligands.

\subsubsection{Rhodium-promoted hydrogenation of $\mathrm{CO}_{2}$}

The macrocyclic rhodium(I) complexes $\mathbf{C} 19 \mathbf{a}$ and $\mathbf{C} 19 \mathrm{~b}$ feature a tetradentate phosphine ligand and an azobenzene moiety spanning the metal centre. The two complexes display one and two carbon units respectively $(n=0,1)$ in the chains tethering the phosphorus functions. They have been specifically designed to investigate the impact of geometry changes on the catalytic hydrogenation of $\mathrm{CO}_{2}$ (Scheme 25). ${ }^{[37]}$

Irradiation of these complexes at $375 \mathrm{~nm}$ converts E-C19 into their Z-isomers C19a' and C19b', as shown by UV and NMR monitoring. The reverse isomerisation takes place slowly $(\mathrm{k}=$ 9.9 $\times 10^{-3}$ and $8.7 \times 10^{-3} \mathrm{~min}^{-1}$ for $\mathbf{C} 19 \mathbf{a}^{\prime}$ and $\mathbf{C} 19 \mathbf{b}^{\prime}$ respectively), with complete relaxation after 6 to 8 hours. (For comparison, the $\mathrm{Z} \rightarrow \mathrm{E}$ isomerization of the 4,4'-diaminoazobenzene precursor in Scheme 21 takes place in $15 \mathrm{~min}$ ). The slowdown is likely due to the restricted flexibility of the macrocyclic complexes. 


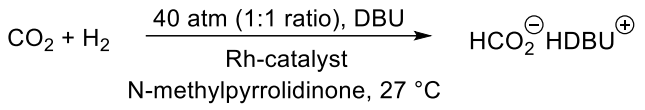

Rh-catalyst:<smiles>CC(C)(C)Nc1ccc(N=Nc2ccc(NC(=O)CN3CCN(c4ccccc4)CC3Pc3ccccc3)cc2)cc1</smiles>

\begin{tabular}{|c|c|c|}
\hline & Catalyst & TOF $\left(h^{-1}\right)$ \\
\hline 1 & $\mathbf{C 1 9 a}$ & $11 \pm 2$ \\
\hline 2 & $\mathbf{C 1 9 a}+\mathrm{hv}, \lambda_{\max } 365 \mathrm{~nm}$ & $16 \pm 2$ \\
\hline 3 & $\mathbf{C 1 9 b}$ & $17 \pm 0.2$ \\
\hline 4 & $\mathbf{C 1 9 b}+\mathrm{hv}, \lambda_{\max } 365 \mathrm{~nm}$ & $18 \pm 0.2$ \\
\hline
\end{tabular}

Scheme 25. Rhodium(I)-promoted hydrogenation of $\mathrm{CO}_{2}$

The hydrogenation experiments have been carried out in a stainless reactor with a sapphire window, under 40 atm of a 1:1 $\mathrm{CO}_{2} / \mathrm{H}_{2}$ mixture, both in the dark and under continuous irradiation. The largest macrocycle c19b $(n=1)$, displayed the same reaction rate under both conditions. On the contrary, irradiation of complex C19a $(n=0)$ led to a more active catalyst, giving a $40 \%$ rate enhancement. In depth theoretical, kinetic and thermodynamic studies of the individual catalytic steps (Scheme 26) showed that the reaction rates do not correlate, in a direct way, with the extent of geometrical changes in the outer coordination sphere induced by irradiation. They do not correlate with the rates of the oxidative addition of $\mathrm{H}_{2}$ on complexes $\mathbf{C} 19$. Finally, it is postulated that the reaction rate should be affected by small changes of the P-Rh-P bite-angles that modulate critically the hydricity (hydride transfer ability) of the rhodium monohydride intermediate II.

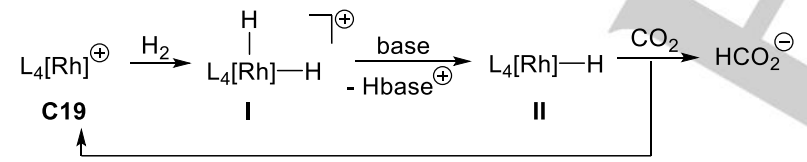

Scheme 26. Key steps of the rhodium-promoted hydrogenation of $\mathrm{CO}_{2}$

This study suggests that geometrical changes of a remote azobenzene moiety, in the outer coordination sphere of a transition metal, can regulate reaction rates by subtle changes of the bite angles at the metal center.

\subsubsection{Ruthenium-promoted release of dihydrogen from ammonia-borane}

Ammonia-boranes, $\mathrm{NH}_{3}-\mathrm{BH}_{3}$, are promising materials for hydrogen storage and subsequent release under metal catalysis The ( $p$-cymene)ruthenium dichloride complexes $\mathbf{C 9}$ have been considered as catalysts for the controlled release of hydrogen from these adducts (Scheme 27). ${ }^{[18 \mathrm{~b}]}$ Complexes $\mathbf{c 9}$ bear the monodentate tris(azobenzene)phosphines $\mathbf{9}$ as photoswitchable ligands.

In complexes C9, the three azobenzene units of the ligands adopt mainly the most stable $E$-form (EEE-isomers), but small amounts of the isomeric EEZ-ligands may be formed, with up to a $25 \%$ amount for C9b. Irradiation of these samples at $324 \mathrm{~nm}$, for 30 min in $\mathrm{CD}_{3} \mathrm{CN}$, induces $\mathrm{E} \rightarrow Z$ isomerization. The reverse $Z$ to $E$ isomerization takes place at $65^{\circ} \mathrm{C}$, with $\tau_{1 / 2}=115$ and 144 min for $\mathbf{C 9 a}$ and $\mathbf{C 9 b}$, respectively.

The ruthenium complexes $\mathbf{C 9}$ enabled the hydrolytic generation of hydrogen from ammonia-borane at a $0.5 \mathrm{~mol} \%$ catalyst loading, in a THF-water mixture.

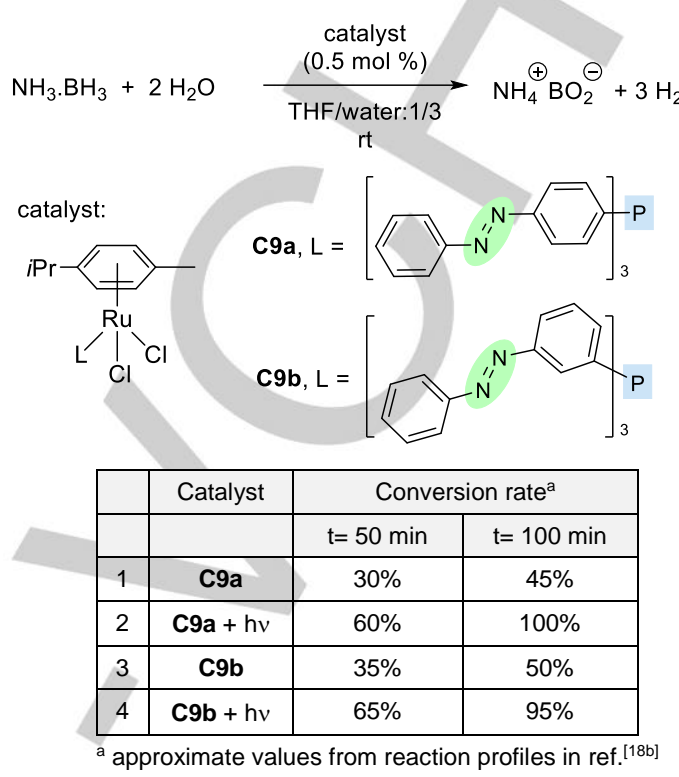

Scheme 27. Ruthenium-promoted $\mathrm{H}_{2}$ release from ammonia-borane

The release of $\mathrm{H}_{2}$ was monitored from pressure evolution, both in the dark and under continuous irradiation (immersion lamp, $125 \mathrm{~W}, 365 \mathrm{~nm}$ ). For both complexes C9, the catalytic activity was much higher under irradiation, compared to dark conditions. In an additional experiment, with catalyst $\mathbf{c} \mathbf{g b}$, irradiation and noirradiation periods were alternated. The reaction profiles clearly showed alternating slopes with different reaction rates.

After several control experiments, including comparison with the model $\left(\mathrm{Ph}_{3} \mathrm{P}\right) \mathrm{Ru}\left(p\right.$-cymene) $\mathrm{Cl}_{2}$ complex, the positive effect of UV irradiation has been assigned to the increased steric bulk of the $Z$-configured phosphorus ligands (increased cone angle). However, the effect couldn't be fully rationalized, mainly due to lack of mechanistic knowledge on this reaction.

Overall, the phosphine-ruthenium complexes $\mathbf{c 9}$ proved to be suitable photoswitchable hydrogen release catalysts. Interestingly, complexes $\mathbf{C 9}$ perform better than analogous ruthenium complexes with azobenzene-derived bipyridine ligands that isomerize less efficiently and suffer dissociation under irradiation.

\subsubsection{Gold(I)-promoted intramolecular hydroaminations}

Our group has reported recently on photoswitchable bimetallic gold complexes of azobenzene-derived diphosphines and their use in the intramolecular hydroamination of $\mathrm{N}$-alkenylureas. ${ }^{[17]}$

The bimetallic complex E-C8 undergoes fast photoisomerization under irradiation at $320 \mathrm{~nm}$ in MeCN (Scheme 28). As shown by UV monitoring, the photostationary state is reached after 60 seconds, with an $E: Z$ ratio $=35: 65$. The reverse process takes place either under irradiation at $406 \mathrm{~nm}(240 \mathrm{sec})$ or under thermal conditions, with an $t_{1 / 2}=278 \mathrm{~h}$ at $60^{\circ} \mathrm{C}$. 


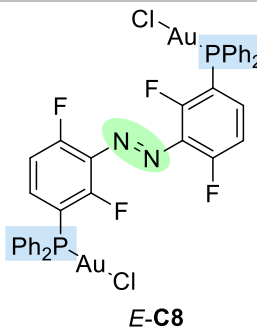

${ }^{31} \mathrm{P}$ NMR, $\delta 25.6\left(J_{P_{-} F}=20 \mathrm{~Hz}\right)$ hv $320 \mathrm{~nm}$

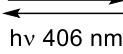
or heating (a)

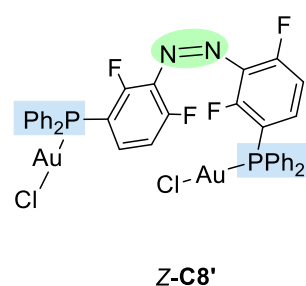

${ }^{31} \mathrm{P}$ NMR, $\delta 24.8$ (broad)
PSS at $320 \mathrm{~nm} \mathrm{E:Z=35:65}$

$\mathrm{PSS}$ at $406 \mathrm{~nm} E: Z=100: 0$

Scheme 28. Photoisomerization of the bimetallic gold complex C8

The fluorine substituents on the azobenzene core make the $Z$ form stable enough to be isolated, characterized by $X$-ray diffraction, and used then in the catalytic tests shown in Scheme 29. The active cationic catalysts were generated from E-C8 and Z-C8' separately, by removing chlorides with $\mathrm{AgSbF}_{6}$. The reaction course was monitored by in situ ${ }^{1} \mathrm{H}$ NMR $\left(\mathrm{CD}_{2} \mathrm{Cl}_{2}\right.$ solutions) with automatic recording.

Both Z- and E-catalysts displayed good catalytic activity in the intramolecular hydroamination reaction, with the $Z$-isomer giving significantly higher reaction rate and conversion (Scheme 29).

(a)

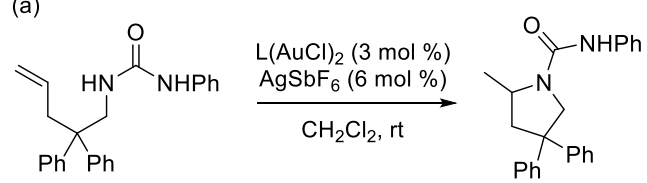

(b)

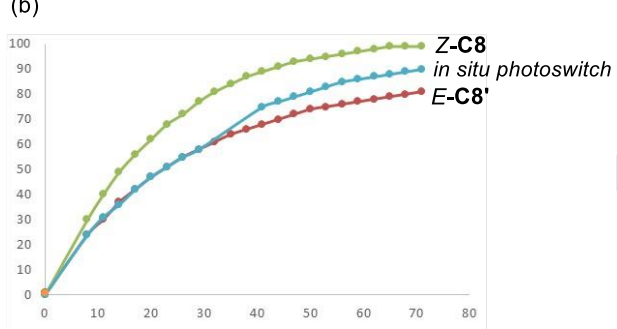

(c)

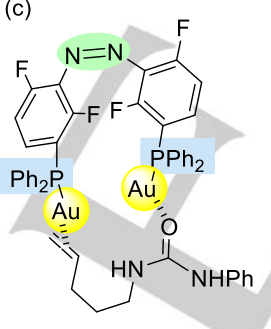

in Scheme 30. In this reaction where synergistic effects between the metals are not expected, the $Z$ - and $E$-forms of the catalyst show the same kinetic profiles.

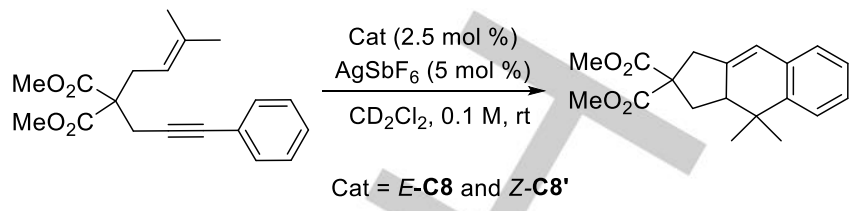

Scheme 30. Enyne cycloisomerisations promoted by the bimetallic gold complexes $\mathbf{C 8}$

Overall, these results validate the working hypothesis on which the study had been built initially, i.e. that bimetallic complexes are especially suited to demonstrate photoswitch phenomena in catalysis, as far as they may enable ON-OFF switch of cooperative effects between the two metals. Beyond the external control of catalytic reactions, bimetallic complexes of this class might also afford unprecedented probes to highlight cooperative effects in bimetallic processes.

\subsection{Catalysts based on dithienylethene diphosphines}

As far as we know, only one example of light-induced modulation of the catalytic activity of metal complexes featuring dithienylethene-phosphines has been reported so far.

\subsubsection{Copper(II)-promoted hydroboration of styrenes}

The bimetallic copper complex $\mathbf{C 2 0}$ has been used as precatalyst in the hydroboration of 4-fluorostyrene (Scheme 31). ${ }^{[38]}$ The active catalyst was generated in situ from $\mathbf{C 2 0}$, by addition of potassium tert-butoxide in the presence of pinacolborane. Hydroboration was performed first in the dark, then, in a second experiment, the active catalyst was irradiated for 20 minutes at $365 \mathrm{~nm}$ before addition of the substrate. Under irradiation, the orange catalyst solution turned red, as expected. The hydroboration reactions were monitored by gas chromatography. In the dark, the hydroboration reaction gave a $62 \%$ yield, while irradiation decreased the yield to $44 \%$.

Scheme 29. (a) Hydroamination reactions promoted by the bimetallic gold complexes C8; (b) Kinetic profiles; (c) Postulated bimetallic activation of the substrate.

Also, an in situ switch experiment was carried out. The experiment started with catalyst E-C8 and then, after $30 \mathrm{~min}$ (at $\sim 55 \%$ conversion rate), the mixture was irradiated at $320 \mathrm{~nm}$ for 10 min to generate $Z \mathbf{Z}$-C8'. Irradiation led to acceleration of the hydroamination reaction, the conversion rates approaching those obtained with preformed Z-C8' under analogous conditions.

After several control experiments, including comparison of $\mathbf{C 8}$ with the azobenzene derived monometallic gold complex $\mathbf{C 7}$ (see Table 1), the higher catalytic activity of the Z-isomer C8' has been assigned to synergistic cooperative effects between the two metal centers. Indeed, in this reaction, a bimetallic activation of the substrate can be postulated (Scheme 29c), that should be enhanced with Z-configured catalysts, owing to the shorter distance between the two metals.

In parallel studies, the same gold complexes $\mathbf{C 8}$ have been used as pre-catalysts in the enyne cycloisomerisation reaction shown

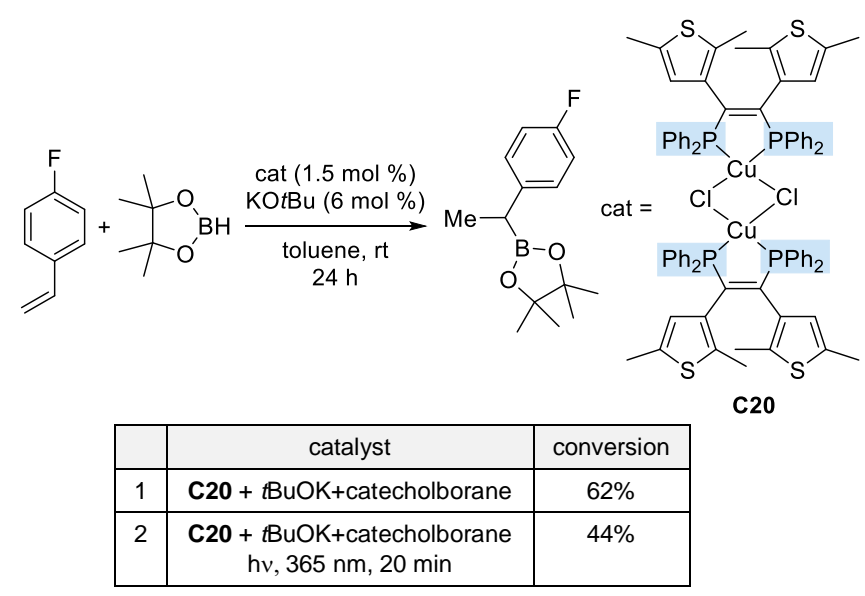

Scheme 31. Copper-catalyzed hydroboration of 4-fluorostyrene.

Based on DFT calculations, the decreased reactivity of the closed form of the catalyst has been tentatively assigned to its 
electronic features, namely to the extended $\pi$-conjugation over the dithiophene backbone that decreases the electron density at the metal center.

\subsection{Catalysts based on biindane-diphosphines}

\subsubsection{Palladium-promoted Heck reactions}

The biindane-derived macrocyclic diphosphine (S)-20 displays an $(S)$-configured biaryl and a cis olefin moiety. When irradiated at $\lambda=365 \mathrm{~nm}$ in $\mathrm{CH}_{2} \mathrm{Cl}_{2}$, it undergoes isomerization into a mixture of two trans-isomers with opposite configurations of the olefinic units (The stiff olefinic moiety adopts a non-planar, chiral configuration). The photostationary state (40 min irradiation) contains a 68:23:9 mixture of cis-20, trans-20'1 and trans-20'2 (Scheme 32). ${ }^{[26]}$

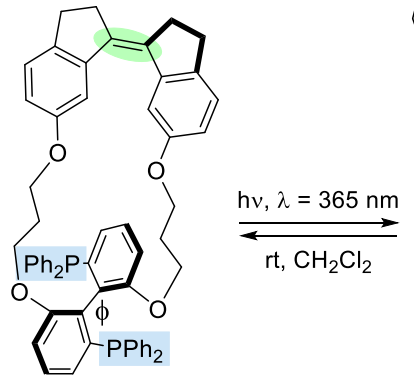

(S)-cis-20, $\phi=83^{\circ}$

$\phi=$ dihedral angle of the atropisomeric biaryl unit (from DFT calculations)

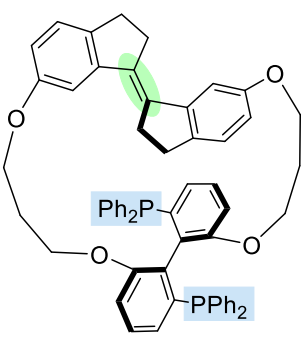

(S)-trans-20'1, $\phi=106^{\circ}$

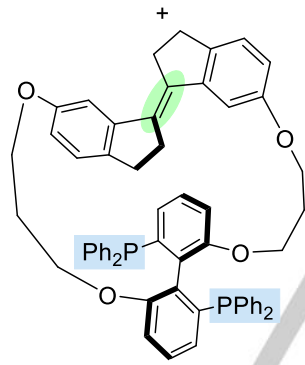

(S)-trans-20,2,$\phi=98^{\circ}$
Scheme 32. Photoisomerization of the biindane-derived diphosphine 20

According to DFT calculations, the three diphosphines have significantly different dihedral angles at the biaryl moiety, with $\phi=$ $83^{\circ}$ for cis-20 (compressed angle), $\phi=106^{\circ}$ for trans-20'1 (extended) and $\phi=98^{\circ}$ for trans-20,2 (virtually undistorted). These compounds have been separated and two of them have been tested as ligands in the enantioselective Pd-promoted Heck reactions in Scheme 33. Also, in situ switch experiments have been carried out to evaluate the catalytic activity of the mixture of palladium catalysts, presumably generated from trans-20'1 under irradiation.

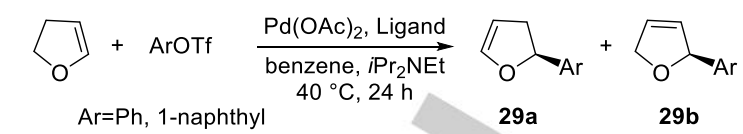

\begin{tabular}{|c|c|c|c|c|c|}
\hline & Ligand & $\begin{array}{l}\text { Dihedral } \\
\text { angle } \phi\end{array}$ & $\begin{array}{c}\text { Conv } \\
\%\end{array}$ & $29 a: 29 b$ ratio & $\begin{array}{c}\mathrm{Ee} \% \\
(S)-29 \mathrm{a}\end{array}$ \\
\hline & & & & $\mathrm{Ar}=\mathrm{Ph}$ & \\
\hline 1 & MeOBiphep & $97^{\circ}$ & 23 & $95: 5$ & 90 \\
\hline 2 & cis-20 & $83^{\circ}$ & 55 & $97: 3$ & 96 \\
\hline 3 & trans-20‘1 & $106^{\circ}$ & 95 & $98: 2$ & 79 \\
\hline \multirow[t]{2}{*}{4} & $\operatorname{trans}-20^{\prime 1}+h v^{a}$ & - & 93 & $97: 3$ & 90 \\
\hline & & & & $\mathrm{Ar}=1$-naphthyl & \\
\hline 5 & MeOBiphep & & 98 & $79: 21$ & 54 \\
\hline 6 & cis-20 & & 91 & $72: 28$ & 60 \\
\hline 7 & trans-20 1 & & $>99$ & $88: 12$ & 13 \\
\hline 8 & $\operatorname{trans}-20^{\prime 1}+h v^{a}$ & & $>99$ & $85: 15$ & 42 \\
\hline
\end{tabular}

a irradiation at $365 \mathrm{~nm}, 3 \mathrm{~W}, 60 \mathrm{~s}$

Scheme 33. Effect of the dihedral angle of the ligands on the enantioselectivity of Heck reactions.

The Heck reactions have been carried out between dihydrofurane and either phenyl- or 1-naphthyl triflate. From these experiments, the level of chiral induction has been correlated to the mechanical distorsion of the dihedral angle of the biaryls, induced by photoisomerization. Starting from phenyl triflate (entries 1-4 in Scheme 33), the ligand with the more compressed dihedral angle, cis-20, affords the 2,3-dihydrofurane 29 with the highest enantiomeric excess $(96 \%$ ee), while trans$20^{\prime 1}$ affords 29 a with only $79 \%$ ee. Thus, in situ irradiation of the catalyst formed from trans-20'1 allow to generate a more efficient catalytic mixture giving an intermediate $90 \%$ ee. The observed effect is assigned exclusively to geometrical changes of the dihedral angles, since the electronic properties of the two isomeric ligands are identical (identical $J_{P-S e}=739 \mathrm{~Hz}$ for the corresponding selenides).

Analogous trends have been observed in the Heck reactions involving 1-naphthyl triflate (entries 5-8 in Scheme 33). In this case, the dihedral angles of the ligands affect also the 29a:29b product ratios. Ligands with larger dihedral angles (trans-18') favor indeed the 2,3-dihydrofurane 29a vs 2,5-dihydrofurane 29b.

In parallel studies, the same ligands cis-20 and trans-20' have been compared in model allylic alkylations. However, in these reactions the mechanical distorsion of the ligands induced only modest changes of the enantioselectivity levels.

This work demonstrates that externally induced photoswitch of a remote structural unit of the ligand can result in the effective actuation of a chiral metal catalyst.

\subsubsection{Palladium-promoted desymmetrization of allylic carbamates}

The second example hereafter also relates to enantioselectivity switch using chiral biindane-derived ligands.

The biindane-based diphosphine $\mathbf{2 3}^{[27]}$ behaves as a light-driven molecular motor, switching reversibly between four different forms, under combined photochemical and thermal conditions (Scheme 34). It displays both a stereogenic carbon with $(R)$ - 
configuration and a hindered olefinic unit with helical chirality $(P$ or $M$-configurations).

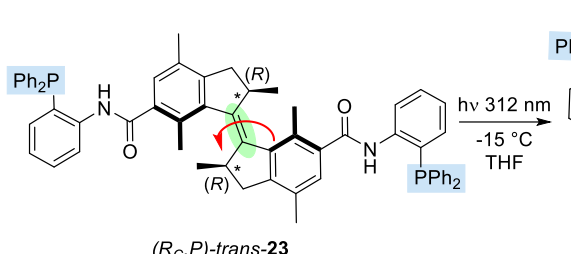

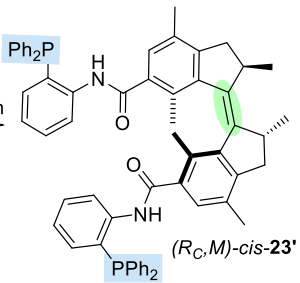<smiles>Cc1cc(C(=O)Nc2cccc(C(F)(F)F)c2Pc2ccccc2)c2c(c1C)/C(=C1\c3c(C)c(C(=O)Nc4ccccc4P)cc(C)c3CC1C)C(C)C2</smiles>

$\left(R_{C}, M\right)$-trans-23 ${ }^{1}$<smiles>Cc1ccccc1P</smiles>
$60^{\circ} \mathrm{C}$

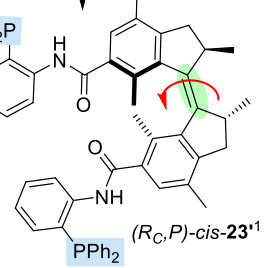

Scheme 34. Four-step cycle of rotary motion of diphosphine 23.

Under UV irradiation (312 nm), the starting diphosphine $\left(R_{c}, P\right)$ trans-23 undergoes photoisomerization into its cis-isomer $(R c, M)$-cis-23' (7:93 trans:cis ratio at the PSS). The process involves a counterclockwise rotation of the indane fragment around the olefin $\mathrm{C}=\mathrm{C}$ axis and leads therefore to inversion of the helical configuration (demonstrated by circular dichroism spectra). The rotation sense is dictated by the $(R)$-configured stereogenic carbon. Then, the $\left(R_{C}, M\right)$-cis-23' isomer tends to convert into the other cis isomer $(R c, P)$-cis-23'1 by thermal inversion of its helical configuration. From this compound, a second photochemical step generates the diphosphine $\left(R_{C}, M\right)$ trans-23 ${ }^{1}$ that couldn't be isolated because it converts into the starting $\left(R_{C}, P\right)$-trans-23 below room temperature. The whole process has been monitored by NMR, UV and CD spectroscopy. The isolated diphosphines $\left(R_{C}, P\right)$-trans-23, $\left(R_{C}, M\right)$-cis-23' and $(R c, P)$-cis-23'1 have been tested separately in the enantioselective intramolecular allylic amination of the mesocarbamate $\mathbf{3 0}$ (Scheme 35 ), with palladium catalysts generated in situ from $\mathrm{Pd}_{2} \mathrm{dba}_{3}$ and the ligands.

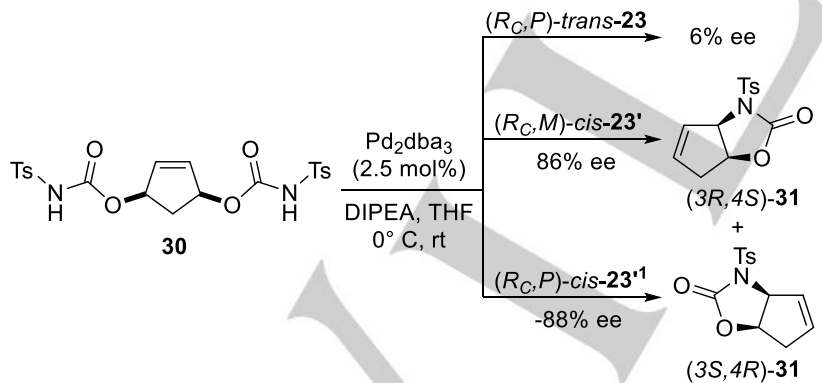

Scheme 35. Stereodivergent synthesis of oxazolidinones via palladium promoted desymmetrization of the meso bis-carbamate $\mathbf{3 0}$.

As expected, the less hindered trans diphosphine $\left(R_{C}, P\right)$-trans23 gives a nearly racemic oxazolidinone $(6 \%$ ee), while the $(M)$ cis-isomer 23', formed by photoisomerisation, promotes the reaction with excellent stereocontrol: $(3 R, 4 S)-\mathbf{3 1}$ was obtained in $90 \%$ yield and $86 \%$ ee. Finally, the $(P)$-cis-isomer $\mathbf{2 3}{ }^{\prime 1}$, thermally generated from $(M)$-cis-23', also gives excellent ee and opposite stereochemical control: $(3 S, 4 R)-\mathbf{3 1}$ was obtained in $85 \%$ yield and $88 \%$ ee.
This result indicates that the sense of chiral induction is dictated mainly by the helical configuration of the biindane unit.

In summary, these studies have highlighted a photoresponsive chiral biindane diphosphine, 23, that achieves unidirectional rotation around its double bond under UV irradiation. The photoswitch provides an isomeric ligand giving largely improved enantioselectivity levels. This process couldn't be translated into an effective catalytic in situ photoswitch procedure, because the palladium catalyst showed only moderate stability under UV and heating.

\section{Non-catalytic applications in organic synthesis}

Beside their use as ligands in organometallic catalysis, azobenzene derived phosphines have found relevant synthetic applications as Staudinger-type reagents. Thus, B.L. Feringa envisioned the Staudinger-Bertozzi ligation as a tool to incorporate photoswitchable azobenzene tags in biological systems. ${ }^{[39]}$ The method consists in reacting the esterfunctionalized azobenzene-phosphines 13 with biomolecules displaying azido functions (Scheme 36b).

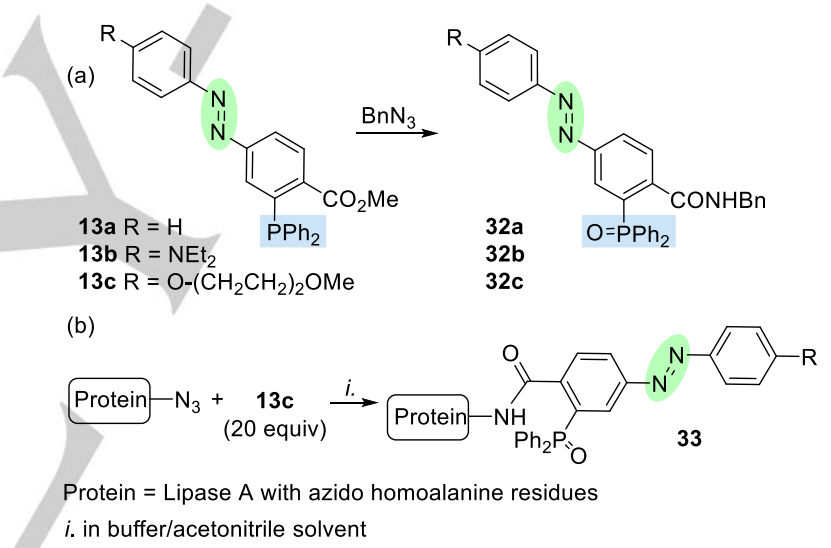

Scheme 36. Azobenzene-derived phosphines for the Staudiger-Bertozzi ligation: (a) model reaction; (b) reaction on azido-functionalized proteins

Azido homoalanine residues (AHA) were introduced at positions 1, 9 and/or 79 of Lipase A from Bacillus subtilis. The azidomodified proteins were incubated then with phosphine $13 \mathrm{c}$ in a TRIS.HCl buffer $(\mathrm{pH} 7.5$, TRIS = tris(hydroxymethyl)aminomethane) / acetonitrile mixture for $22 \mathrm{~h}$. This procedure led to incorporation of up to three azobenzene molecular switches into the enzyme. Singly, doubly and triply modified bioconjugated could be identified by ESI/MS deconvolution.

The photoswitch process has not been investigated so far on these azobenzene-modified proteins. However, it has been demonstrated that the model azobenzene amide 32a (Scheme 36a) displays efficient photoswitch under irradiation at $\lambda=365$ $\mathrm{nm}$ ( $80 \%$ cis-isomer at the PSS state in aqueous buffer). The thermal $\mathrm{Z} \rightarrow \mathrm{E}$ conversion is slow, but it can be accelerated by irradiation with white light. These features are highly suitable for the targeted biochemical applications. Further studies ${ }^{[22]}$ highlighted then that the switch process, and the stability of the $Z$-forms of the phosphine oxides $\mathbf{3 2}$ depend crucially on the nature of the $\mathrm{R}$ substituent. Interestingly, the amino-substituted azobenzene $\mathbf{3 2} \mathbf{b}$ could be isomerized under visible light (532 $\mathrm{nm})$. 
The same phosphines 13 have been used to introduce azobenzene photoswitches into an homoalanine-modified peptide (Sp1-f3 zinc finger), as well as on suitably functionalized quartz surfaces, as illustrated in Scheme 37..22, 39]<smiles>CC(C)(C)[SiH2]CCCNC(=O)OCCN</smiles><smiles>[R]c1ccc(N=Nc2ccc(C(=O)NCCOC(=O)NCCC[SiH2]C(C)(C)C)c([PH](=O)P)c2)cc1</smiles>

Scheme 37. Modification of quartz surfaces with azobenzene

Surface changes resulting from $E$ - to $Z$-isomerization have been highlighted under irradiation at $365 \mathrm{~nm}$.

In summary, azobenzene-derived phosphines allow the introduction of azobenzene units in biologically relevant substrates through Staudinger-Bertozzi ligations. Nevertheless, biomedical applications of these azobenzene tags still face highly challenging requirements, such as the thermal stability of $Z$-azobenzenes in aqueous biological media and implementation of photoresponsive processes under the deeper penetrating visible light.

Phosphorus functionalized azobenzenes have been considered also for applications in material sciences that are outside the scope of this minireview.

\section{Conclusions}

The remote spatio-temporal control of catalytic reactions by means of photoresponsive catalysts represents today a major but still challenging objective. As demonstrated by this short survey, photoswitchable phosphines might play a significant role in the field, as privileged ligands for transition metal complexes enabling highly diverse catalytic processes.

Thus, for instance, photoinduced isomerisation of phosphinecoordinated catalysts allowed to regulate the rate of $\mathrm{Rh}$ promoted hydrogenation of $\mathrm{CO}_{2}$ (section 4.1.2), Ru-promoted release of $\mathrm{H}_{2}$ from ammonia-borane (section 4.1.3), $\mathrm{Pd}$ promoted decarboxylations (section 4.1.1) and copper promoted hydroborations of styrenes (section 4.2.1) The in situ $E \rightarrow Z$ isomerisation of azobenzene-diphosphine gold complexes has been shown to accelerate an intramolecular hydroamination reaction (section 4.1.4). Moreover, photoisomerization of biindane-derived ligands has been shown to control product ratios and enantioselectivity levels in Heck reactions, as well as in some intramolecular allylic aminations, under Pd-catalysis (sections 4.3.1 and 4.3.2).

When the phosphorus functions are close to the photoswitch units, photoisomerization is expected to induce significant changes of both geometrical features and electronic properties of the ligands. A clear-cut example is that of dithienylcyclopentene derived phosphines, where the closed forms display lower $\sigma$-donating ability than the open forms. Nevertheless, this well-established effect must not conceal that, in most instances, tuning of the catalytic behaviour has not been correlated to tuning of the stereoelectronic descriptors ${ }^{[40]}$ of the ligands. Most often, only rather speculative rational has been given, and therefore the rational design of switchable ligands remains largely unattainable.

To find rational to catalytic behaviors is even more challenging when the photoswitch unit is remote from the phosphorus functions and the catalytic activity is modulated by subtle conformational changes of the ligand backbones in the outer coordination sphere (sections 4.1.2, 4.3.1 and 4.3.2).

Another current limitation of in situ photoswitch catalysis is that irradiation usually leads to incomplete isomerization of the catalysts (mixtures are formed at the photostationary states), which lowers consequently the amplitude of the photochemically-induced catalytic tuning. Also, thermal backisomerization can take place spontaneously, notably with azobenzene-derived ligands, if continuous irradiation can't be applied during the whole catalytic process.

As a consequence of these practical limitations, but also of an insufficient differentiation of the isomeric forms of the known ligands, a pure 'on-off' catalytic system based on photoswitchable phosphines remains to be demonstrated. Toward this goal, the design of new and improved ligands is eagerly awaited.

Although sparse, the pioneering reports summarized in this minireview highlight the huge potential of photoresponsive phosphorus ligands, the scope and current limitations of the field, and pave the way to further investigations. 
Vincent Delattre studied chemistry at the National Graduate School of Chemistry of Montpellier (ENSCM) where he obtained his Master Degree in 2018 After two internships in pharmaceutical companies, he started his $\mathrm{PhD}$ at the ICSN, under the supervision of $\mathrm{Dr} A$ Marinetti, working on photoswitchable bifunctional phosphines and applications in catalysis.

Nawel Goual was awarded with a M. Sc. degree in 2018 from the Université ParisEst Créteil (UPEC). She got trainings at the Institut de Chimie et Matériaux Paris Est in 2016-17 and at the ICSN in 2018 . In October 2018, she joined the 'Phosphorus Chemistry and Catalysis' group at the ICSN as a PhD student, under the supervision of Dr. A. Voituriez. Her PhD work focuses on the development of new photoswitchable backbones and the synthesis and photoresponsive diphosphines.

Angela Marinetti is a CNRS Research Director. She started her career in 1981 as a member of the research group headed by Dr François Mathey (CNRS, Ecole Polytechnique). In 1997 she moved to the ChimieParisTech Engineering School (former ENSCP) and in 2005 she joined the ICSN as a team leader. From 2015 to 2019 she has been Director of this Institute. Her current scientific interests are mainly related to the design, synthesis and catalytic applications of chiral phosphorus ligands and organocatalysts.

Fabrizio Medici was awarded with a $M$. Sc. degree in 2014 from the University of Insubria (Italy). He obtained a PhD in Molecular Chemistry in 2017 at Sorbonne Université (Paris), under the supervision of Prof. L. Fensterbank and Dr. G. Lemiere. In 2018 he joined the ICSN as a post-doctoral fellow, working on photoswitchable diphosphine gold(I) complexes under the supervision of $\mathrm{Dr}$. A. Marinetti and Dr. A. Voituriez. Since 2019, he holds a post-doctoral position at the University of IVIIan, working with Prof. M. Benaglia and Pr. A. Puglisi.
Arnaud Voituriez received his Ph.D. from the University of Paris-Sud (Orsay) in 2004, under the supervision of Dr. E. Schulz. After post-doctoral trainings in the groups of Prof A.B. Charette (Montreal, Canada) and Prof F. Chemla (Paris VI, France) he was appointed at the CNRS in 2007, at the ICSN. In 2012 he received his HDR diploma (Habilitation to conduct research) and became a CNRS Research Director in

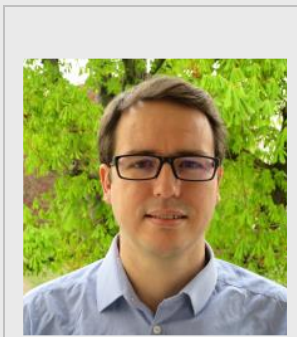
2016. His current research interests include: 1) Synthesis of new chiral phosphines and applications in asymmetric organocatalysis; 2) Synthesis of new phosphahelicenes; 3) Enantioselective gold(I)catalysis and applications in synthesis; 4) Development of new

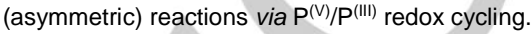

\section{Acknowledgements}

Authors acknowledge financial support from ANR (Switch-Phos ANR-17-CE07-0032) and CHARMMMAT Labex (ANR-11-LABX0039).

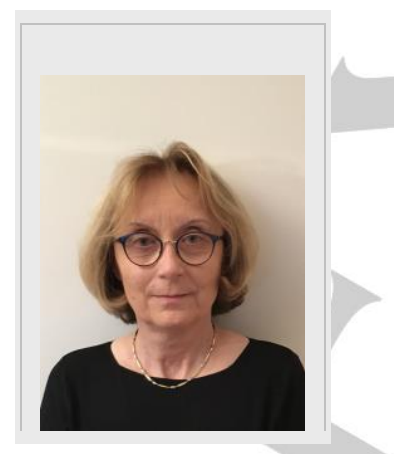

Keywords: photoswitchable phosphines • azobenzenes • dithienylethenes $\bullet$ biindanes $\bullet$ organometallic catalysis 


\section{Entry for the Table of Contents}
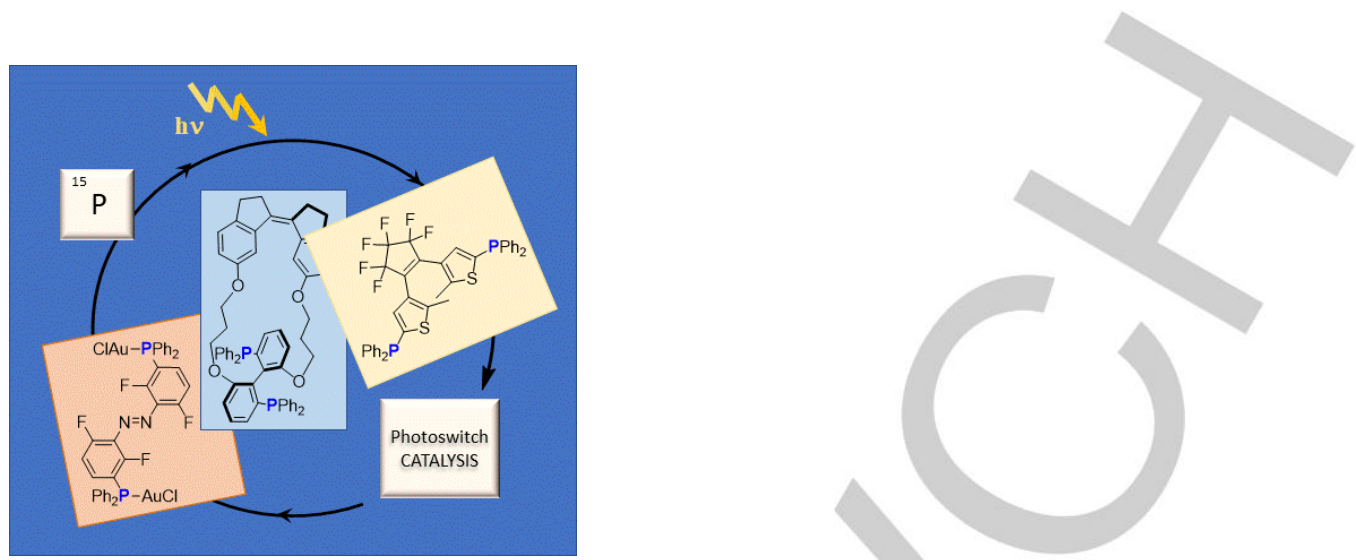

The spatio-temporal control of catalytic processes through external stimuli is currently pursued notably by means of photoresponsive phosphorus ligands. This minireview illustrates this field by summarizing the state of art in the design of azobenzene, dithienylethene and biindane-derived trivalent phosphines. Examples of photoswitch effects on the catalytic activity, regioselectivty and enantioselectivity are outlined.

[1] a) W. Szymanski, J. M. Beierle, H. A. V. Kistemaker, W. A. Velema, B. L. Feringa, Chem. Rev. 2013, 113, 6114-6178; b) K. Hull, J. Morstein, D. Trauner, Chem. Rev. 2018, 118, 10710-10747.

[2] X. Huang, T. Li, J. Mater. Chem. C 2020, 8, 821-848.

[3] a) D. Dattler, G. Fuks, J. Heiser, E. Moulin, A. Perrot, X. Yao, N. Giuseppone, Chem. Rev. 2020, 120, 310-433; b) S. ErbasCakmak, D. A. Lieigh, C. T. McTernan, A. L. Nussbaumer, Chem. Rev. 2015, 115, 10081-10206; c) F. Lancia, A Ryabchun, N. Katsonis, Nature Rev. Chem. 2019, 3, 536-551; d) M. S. Baroncini, S., A. Credi, Chem. Rev. 2020, 120, 310433.

[4] H. Nie, J. L. Self, A. S. Kuenstler, R. C. Hayward, J. R. de Alanlz, Adv. Optical Mater. 2019, 7, 1900224.

[5] C.-L. Sun, C. Wang, R. Boulatov, ChemPhotoChem 2019, 3, 268-283.

[6] a) R. S. Stoll, S. Hecht, Angew. Chem. Int. Ed. 2010, 49 5054-5075; b) B. M. Neilson, C. W. Bielawski, ACS Catal 2013, 3, 1874-1885; c) V. Blanco, D. A. Leigh, V. Marcos, Chem. Soc. Rev. 2015, 44, 5341-5370; d) R. Dorel, B. L. Feringa, Chem. Commun. 2019, 55, 6477-6486; e) Z. Freixa, Catal. Sci. technol. 2020, 10, 3122-3139.

[7] D. Sud, T. B. Norsten, N. R. Branda, Angew. Chem. Int. Ed. 2005, 44, 2019-2021.

[8] a) B. M. Neilson, C. W. Bielawski, J. Am. Chem. Soc. 2012 134, 12693-12699; b) B. M. Neilson, C. W. Bielawski, Organometallics 2013, 32, 3121-3128; c) A. J. Teator, H. Shao, G. Lu, P. Liu, C. W. Bielawski, Organometallics 2017, 36, 490497.

[9] a) R. S. Stoll, M. V. Peters, A. Kuhn, s. Heiles, R. Goddard, M. Bühl, C. M. Thiele, S. Hecht, J. Am. Chem. Soc. 2009, 131 357-367; b) J. Wang, B. L. Feringa, Science 2011, 331, 1429 1432; c) T. Imahori, R. Yamaguchi, S. Kurihara, Chem. Eur. J. 2012, 18, 10802-10807; d) D. Wilson, N. R. Branda, Angew. Chem. Int. Ed. 2012, 51, 5431-5434; e) L. Osorio-Planes, C. Rodríguez-Escrich, M. A. Pericàs, Org. Lett. 2014, 16, 17041707; f) R. Dorel, B. L. Feringa, Angew. Chem. Int. Ed. 2020 59, 785-789; g) M. Vlatkovic, J. Volarić, B. S. L. Collins, L. Bernardi, B. L. Feringa, Org. Biomol. Chem. 2017, 15, 82858294

[10] H. M. D. Bandara, S. C. Burdette, Chem. Soc. Rev. 2012, 41 , 1809-1825.

[11] a) M. Irie, Chem. Rev. 2000, 100, 1685-1716; b) H. Tian, S. Yang, Chem. Soc. Rev. 2004, 33, 85-97; c) M. Irie, T. Fukaminato, K. Matsuda, S. Kobatake, Chem. Rev. 2014, 114, 12174-12277.
[12] a) C. García-Iriepa, M. Marazzi, L. M. Frutos, D. Sampedro, RSC Advances 2013, 3, 6241-6266; b) V. Garcia-López, D. Liu, J. M. Tour, Chem. Rev. 2020, 120, 79-124; c) D. Villarón, S. J. Wezennerg, Angew. Chem. Int. Ed. 2020, 59, doi.org/10.1002/anie.202001031

[13] a) M. J. Alder, K. R. Flower, R. G. Pritchard, Tetrahedron Lett. 1998, 39, 3571-3574; b) M. J. Alder, W. I. Cross, K. R. Flower R. G. Pritchard, J. Chem. Soc. Dalton Trans 1999, 2563-2573 c) M. J. Alder, V. M. Bates, W. I. Cross, K. R. Flower, R. G. Pritchard, J. Chem. Soc. Perkin Trans. 1 2001, 2669-2675

[14] M. Kawamura, R. Kiyotake, K. Kudo, Chirality 2002, 14, 724 726.

[15] a) K. Chane-Ching, M. Lequan, R. M. Lequan, C. Runser, $M$ Barzoukas, A. Fort, J. Mater. Chem. 1995, 5, 649-652; b) M Lequan, L. R.M., K. Chane-Ching, P. Bassoul, G. Bravic, Y Barrans, D. Chasseau, J. Mater. Chem. 1996, 6, 5-9; cC. Lambert, E. Schmälzlin, K. Meerholz, C. Bräuchle, Chem. Eur. J. 1998, 4, 512-521.

[16] M. Yamamura, N. Kano, T. Kawashima, Inorg. Chem. 2006, 45, 6497-6507.

[17] T. Arif, C. Cazorla, N. Bogliotti, N. Saleh, F. Blanchard, V. Gandon, R. Métivier, J. Xie, A. Voituriez, A. Marinetti, Catal. Sci. Technol. 2018, 8, 710-715.

[18] a) M. D. Segarra-Maset, P. W. N. M. van Leeuwen, Z. Freixa Eur. J. Inorg. Chem. 2010, 2075-2078; b) A. Telleria, P. W. N. M. Van Leeuwen, Z. Freixa, Dalton Trans 2017, 46, 3569-3578.

[19] a) M. Yamamura, N. Kano, T. Kawashima, J. Am. Chem. Soc. 2005, 127, 11954-11955; b) M. Yamamura, N. Kano, T. Kawashima, Bull. Chem. Soc. Jpn 2012, 85, 110-123.

[20] E. Besson, V. Mehdi, V. Matsura, Y. Guari, C. Reyé, R. J. P Corriu, Chem. Commun. 2005, 1775-1777.

[21] H. Bricout, E. Banaszak, C. Len, F. Hapiot, E. Monflier, Chem. Commun. 2010, 46, 7183-7185.

[22] C. Poloni, W. Szymański, L. Hou, W. R. Browne, B. L. Feringa Chem. Eur. J. 2014, 20, 946-951.

[23] D. Sud, R. McDonald, N. R. Branda, Inorg. Chem. 2005, 44 5960-5962.

[24] J. Yin, Y. Lin, X. F. Cao, G. A. Yu, H. Y. Tu, S. H. Liu, Dyes and Pigments 2009, 81, 152-155.

[25] G. Bianchini, G. Strukul, D. F. Wass, A. Scarso, RSC Adv. 2015, 5, 10795-10798.

[26] Z. S. Kean, S. Akbulatov, Y. Tian, R. A. Widenhoefer, R Boulatov, S. L. Craig, Angew. Chem. Int. Ed. 2014, 53, 14508145011.

[27] D. Zhao, T. M. Neubauer, B. L. Feringa, Nat. Commun. 2015 6:6652 doi: $6610.1038 /$ ncomms 7652 . 
[28] M. Vlatkovic, L. Bernardi, E. Otten, B. L. Feringa, Chem. Commun. 2014, 50, 7773-7775.

[29] R. Costil, S. Crespi, L. Pfeifer, B. L. Feringa, Chem. Eur. J. 2020, 26, 7783-7787.

[30] M. J. Alder, W. I. Cross, K. R. Flower, R. G. Pritchard, J. Organomet. Chem. 1999, 590, 123-128.

[31] M. J. Alder, K. R. Flower, R. G. Pritchard, J. Organomet. Chem. 2001, 629, 153-159.

[32] M. J. Alder, W. I. Cross, K. R. Flower, R. G. Pritchard, J. Organomet. Chem. 1998, 568, 279-285.

[33] N. Kano, M. Yamamura, X. Meng, T. Yasuzuka, T. Kawashima, Dalton Trans 2012, 41, 11491-11496.

[34] J. Liang, J. Yin, Z. Li, C. Zhang, D. Wu, S. H. Liu, Dyes and Pigments 2011, 91, 364-369.
[35] F.-R. Dai, B. Li, L.-X. Shi, L.-Y. Zhang, Z.-N. Chen, Dalton Trans. 2009, 10244-10249.

[36] B. Li, Y.-H. Wu, H.-M. Wen, L.-X. Shi, Z.-N. Chen, Inorg. Chem. 2012, 51, 1933-1942.

[37] N. Priyadarshani, B. Ginovska, J. T. Bays, J. C. Linehan, W. J. Shaw, Dalton Trans. 2015, 44, 14854-14864.

[38] Z. Xu, Y. Cao, B. O. Patrick, M. O. Wolf, Chem. Eur. J. 2018, 24, 10315-10319.

[39] W. Szymański, B. Wu, C. Poloni, D. B. Janssen, B. L. Feringa, Angew. Chem. Int. Ed. 2013, 52, 2068-2072.

[40] a) D. J. Durand, N. Fey, Chem. Rev. 2019, 119, 6561-6594; b) L. Falivene, Z. Cao, A. Petta, L. Serra, A. Poater, R. Oliva, V. Scarano, L. Cavallo, Nature Chem. 2019, 11, 872-879. 